\title{
Synthèse Bibliographique sur des Paramètres Biologiques et Zootechniques du Poisson-chat Africain Clarias gariepinus Burchell, 1822
}

Edéa Olayèmi Géoffroy, Laboratoire de Biotechnologies et d'Amélioration (LaBAA) à l'Institut des Sciences Biomédicales Appliquées (ISBA) - Faculté des Sciences Agronomiques - Université d'Abomey-Calavi, Cotonou, Bénin Hinvi Lambert Cloud,

Laboratoire d'Hydrologie et d'Aquaculture, Faculté des Sciences Agronomiques - Université d'Abomey-Calavi, Cotonou, Bénin Abou Youssouf,

Laboratoire d'Hydrologie Appliquée, Faculté des Sciences et Techniques, Université d'Abomey-Calavi, Bénin

\section{Gbangboche Armand Bienvenu,}

Laboratoire de Biotechnologies et d'Amélioration Animale (LaBAA), Institut des Sciences Biomédicales Appliquées (ISBA), Faculté des Sciences Agronomiques- Université d'Abomey-Calavi, Cotonou, Bénin

Ecole de Gestion et d'Exploitation des Systèmes d'Elevage Université Nationale d'Agriculture, République du Bénin

Doi:10.19044/esj.2019.v15n27p54 ～URL:http://dx.doi.org/10.19044/esj.2019.v15n27p54

\section{Résumé}

Le présent article de revue fait l'inventaire des différentes contributions scientifiques et techniques relatives aux paramètres biologiques et zootechniques du poisson-chat Clarias gariepinus. Plusieurs années d'efforts de recherches montrent que Clarias gariepinus revêt une grande importance en pêche et aquaculture en Afrique et dans le monde entier, si l'on en juge la masse des connaissances produites. Les informations fournies dans cette synthèse ont été recueillies à partir d'articles scientifiques, de livres et manuels, de rapports techniques, de thèses, de mémoires, puis de communications scientifiques. Les auteurs, au travers d'un inventaire des différentes contributions scientifiques et techniques de 1971 à 2017, ont rapporté les caractéristiques biologiques de C. gariepinus, son régime alimentaire et nutritionnel, sa reproduction, ses performances de croissance, les systèmes et dispositifs de son élevage et quelques maladies auxquelles il 
est sujet. Les caractéristiques biologiques du poisson-chat africain ont été analysées à partir de sa description, sa classification taxonomique, son habitat, ses exigences écologiques et sa distribution géographique. Le régime alimentaire de l'espèce a été abordé dans le milieu naturel, en élevage et au travers des besoins nutritionnels et les contraintes afférentes. La reproduction de l'espèce quant à elle comporte, l'âge à la première maturité sexuelle, la durée d'incubation, l'indice gonado-somatique, la fécondité absolue, la fécondité relative et la fréquence de ponte. Les performances de croissance ont pris en compte le gain de poids et le taux de croissance spécifique. Enfin, les systèmes et dispositifs d'élevage et quelques maladies de $C$. gariepinus ont été passés en revue.

Mots-clés:Clarias gariepinus, reproduction, alimentation, croissance, élevage 


\title{
Biological and zootechnical characteristics of the African catfish Clarias gariepinus Burchell, 1822
}

\section{Edéa Olayèmi Géoffroy,}

Laboratoire de Biotechnologies et d'Amélioration (LaBAA) à l'Institut des

Sciences Biomédicales Appliquées (ISBA) - Faculté des Sciences

Agronomiques - Université d'Abomey-Calavi, Cotonou, Bénin

\section{Hinvi Lambert Cloud,}

Laboratoire d'Hydrologie et d'Aquaculture, Faculté des Sciences

Agronomiques - Université d'Abomey-Calavi, Cotonou, Bénin

\section{Abou Youssouf,}

Laboratoire d'Hydrologie Appliquée, Faculté des Sciences et Techniques,

Université d'Abomey-Calavi, Bénin

\section{Gbangboche Armand Bienvenu,}

Laboratoire de Biotechnologies et d'Amélioration Animale (LaBAA), Institut des Sciences Biomédicales Appliquées (ISBA), Faculté des Sciences

Agronomiques- Université d'Abomey-Calavi, Cotonou, Bénin

Ecole de Gestion et d'Exploitation des Systèmes d'Elevage

Université Nationale d'Agriculture, République du Bénin

\begin{abstract}
This review article set out the inventory of the various scientific and technical contributions on the biological and zootechnical parameters of the catfish Clarias gariepinus. Several years of research shows that Clarias gariepinus is of great importance in fisheries and aquaculture in Africa and around the world, judging by the wealth of knowledge produced. The information provided in this review was collected from scientific articles, books and handbooks, technical reports, thesis, dissertations, and proceedings. The authors, through an inventory of the various scientific and technical contributions from 1971 to 2017, reported the biological characteristics of $C$. gariepinus, its diet and nutrition, its reproduction, its growth performance, its breeding systems and devices and some diseases to which it is subject. The biological characteristics of the African catfish were analyzed based on its description, taxonomic classification, habitat, ecological requirements and geographic distribution. The diet of the species has been addressed within its natural environment, in rearing and through nutritional needs and constraints. Reproduction of the species includes, age at first sexual maturity, incubation
\end{abstract}


time, gonado-somatic index, absolute fertility, relative fertility and spawning frequency. Growth performance took into account the weight gain and the specific growth rate. Finally, breeding system and device and some diseases of $C$. gariepinus were reviewed.

Keywords: Clarias gariepinus, Reproduction, Feeding, Growth, Breeding

\section{Introduction}

Parmi les 32 espèces du genre clarias représentées en Afrique, Clarias gariepinus Burchell, 1822 revêt une grande importance commerciale en pêche et aquaculture tant sur le continent africain que le reste du monde. Son expansion est due à ses attributs zootechniques qui incluent une vitesse de croissance plus rapide, une résistance aux maladies et une possibilité de stockage à densité élevée (Wiecaszek et al., 2010). Les caractéristiques qui font de C. gariepinus un excellent candidat pour la pisciculture intensive sont multiples : (1) ses géniteurs produisent de grandes quantités d'œufs et de sperme toute l'année, (2) il accepte une grande variété d'aliments artificiels bon marché, (3) il supporte des densités élevées en conditions d'élevage, (4) il tolère de mauvaises conditions environnementales (Hecht, Oellermann et Verheust, 1996) et (5) sa chair est très appréciée par une grande frange de la population africaine, donc sa commercialisation facile (Pruszynski, 2003 ; Ahotondji, 2012). Leur capacité à survivre hors de l'eau pendant de longues périodes en font des poissons de choix pour l'aquaculture dans les pays tropicaux (Pillay, 1990). Il existe de plus des variétés de cette espèce acclimatée aux hautes altitudes et aux faibles températures, telles que celles qui prévalent au Rwanda (Kanangire, 2001). Par ailleurs, d'après Legendre et al. (1992), sur le plan aquacole, C. gariepinus est l'espèce la plus élevée à cause de sa grande capacité de tolérance des eaux, sa croissance rapide et son prix élevé sur le marché, son alimentation constituée des résidus ménagers, ainsi que de tout aliment disponible incluant les planctons, les larves d'insectes, les vers de terre et les détritus (Mfwana et al., 2016). Il est également capable de se reproduire en captivité et d'atteindre une taille de 7 $\mathrm{kg}$ (Holden et Reed, 1978; Idodo-Umeh, 2003). Il convertit efficacement les aliments, en particulier les mâles (Nweke et Ugwumba, 2005). Bien qu'il existe des informations scientifiques relatives à tous les aspects d'élevage de cette espèce, beaucoup d'effort reste à faire pour renforcer sa production dans les pays en développement et au Bénin en particulier en vue de satisfaire la demande sans cesse croissante. Le but de cette revue est d'inventorier les différents travaux portant sur l'élevage de Clarias gariepinus Burchell, 1822 et d'en faire une synthèse sur les caractéristiques biologiques et zootechniques de cette espèce. 


\section{Méthodologie}

Les auteurs ont cherché à décrire les paramètres biologiques et zootechniques de Clarias gariepinus, au travers d'une diversité des contributions scientifiques et techniques de 1971 à 2017. Les informations obtenues ont permis d'élucider la taxonomie et la morphologie de $C$. gariepinus, sa distribution géographique, son habitat et ses exigences écologiques, son régime alimentaire et ses besoins nutritionnels, la formulation et la présentation des aliments. Les performances de reproduction ont été détaillées au travers de sept critères : l'âge à la maturité sexuelle, la ponte, incubation, éclosion et fécondité, le contrôle de reproduction et hybridation. La description de la croissance a pris en compte le système et dispositif d'élevage et les facteurs d'influence. Enfin, les maladies de C. gariepinus ont été passées en revue.

\section{Résultats}

Taxonomie et description morphologique de Clarias gariepinus Burchell, 1822.

Les caractéristiques taxonomiques (Diallo et Thiam, 2010) du poissonchat africain Clarias gariepinus Burchell, 1822 sont les suivantes :

$\begin{array}{ll}\text { Règne } & \text { Animal } \\ \text { Embranchement } & \text { Chordatés } \\ \text { Sous-embranchement } & \text { Vertébrés } \\ \text { Super-classe } & \text { Ostéichtyens } \\ \text { Sous-classe } & \text { Neopterygii } \\ \text { Super-ordre } & \text { Acanthopterygii } \\ \text { Ordre } & \text { Siluriformes } \\ \text { Famille } & \text { Clariidés } \\ \text { Genre } & \text { Clarias } \\ \text { Nom binominal } & \text { Clarias gariepinus }\end{array}$

Le genre Clarias est un des douze genres de Clariidae présents en Afrique ; il est subdivisé en six sous-genres (Richir, 2004). Les Clariidae se distinguent d'une part des autres Siluriformes par l'absence d'épine à la nageoire dorsale, des nageoires dorsale et anale très longues, un corps de type anguilliforme. D'autre part, ils sont caractérisés par la présence de quatre paires de barbillons et d'un organe suprabranchial, formé par des évaginations $\mathrm{du}$ deuxième et du quatrième arc branchial, permettant aux poissons de pratiquer une respiration aérienne (Fermon, 2011). Clarias gariepinus (Figure 1) ou poisson-chat se caractérise par une tête large (Lacroix, 2004), aplatie dorso-ventralement en forme de pelle (Das et Ratha, 1996). Il possède un maxillaire réduit, une bouche non protactile (Vandewalle, 2002) dépourvue de 
dents en formes d'incisive (Bruton, 1996). Les dents chez cette espèce sont souvent petites et portées par des bandes prémaxillaires vomériennes, pharyngiennes ou mandibulaires servant à garder la proie dans la bouche que de la lacérer (Das et Ratha, 1996). Un appareil suprabranchial formé par des structures arborescentes aux parois fortement vascularisées permet à ce poisson de respirer l'air atmosphérique (Richir, 2004). Le poisson-chat africain est aussi caractérisé par un corps allongé (Richir, 2004; Coppens, 2012) et sans écailles ; ce qui facilite sa sinuosité (Bruton, 1996). La peau dure, couverte de mucus est utilisée dans la respiration cutanée pour suppléer la respiration aquatique chez plusieurs espèces. Par ailleurs, $C$. gariepinus est doté de longues nageoires dorsale toujours sans épine et anale ; la nageoire pectorale possède une forte épine (Richir, 2004; Coppens, 2012). Il est pourvu d'organes sensoriels non visuels bien développés : les barbillons péribuccaux, qui servent essentiellement à détecter la nourriture (Bruton, 1996 ; Baras et Lalèyè, 2003).

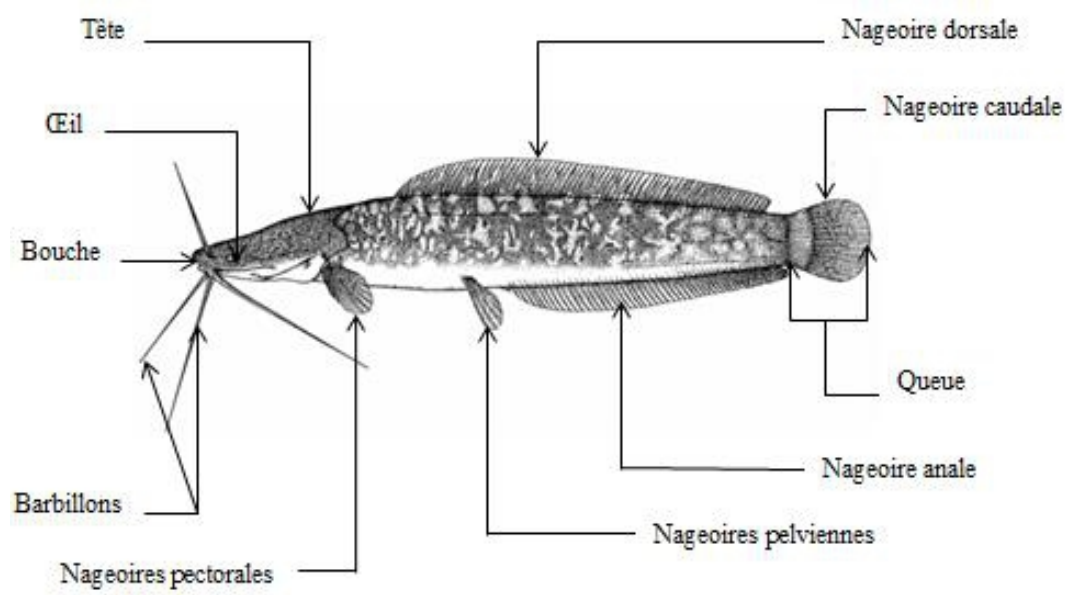

Figure 1 : Clarias gariepinus Burchell, 1822 (Paugy, Lévêque et Teugels, 2004)

\section{Distribution géographique, habitat et exigences écologiques}

La distribution de Clarias gariepinus est presque panafricaine. En Afrique de l'Ouest, l'espèce est commune dans le lac Tchad, dans les bassins du Chari et du Logone, de la Bénoué, du Niger, de l'Oshun, de l'Ogun, de l'Ouémé, du Mono, de la Volta, du Bandama, de la Haute Comoé et du Sénégal. Elle n'a pas été retrouvée dans la Gambie ni dans les bassins côtiers de Guinée (à l'exception d'un exemplaire de Kindia), de Sierra Leone, du Libéria et de Côte d'Ivoire (à l'Ouest du bassin du Bandama). Elle est également absente du bassin de la Cross (Paugy, Lévêque et Teugels, 2004). Dans le nord et le centre de l'Afrique, il a été décrit sous le nom de C. lazera, dans la région orientale sous celui de $C$. senegalensis, dans la partie 
occidentale, C. mossambicus et dans la partie méridionale, C. gariepinus. Il s'agit cependant, dans toutes ces régions, d'une seule espèce, C. gariepinus (Viveen et al., 1985). Plusieurs autres synonymes rappelés par Fermon (2011) ont été utilisés pour désigner la même espèce. C. gariepinus a largement été introduit en Europe et dans le reste de l'Asie pour son élevage (Van Weerd, 1995).

Pour l'habitat et l'écologie de C. gariepinus, Anusuya et al. (2017) signalent pour sa survie et sa croissance, la nécessité d'une bonne qualité de l'eau. En effet, l'eau joue donc un rôle important dans la santé des poissons et sa détérioration est facteur de stress (Arulampalam et al., 1998). Certains facteurs liés à la qualité de l'eau sont plus susceptibles d'être impliqués dans les pertes de poissons tels que l'oxygène dissous, la température et l'ammoniac. D'autres, tels que le $\mathrm{pH}$, l'alcalinité, la dureté et la clarté affectent les poissons, mais ne sont généralement pas directement toxiques. Chaque facteur de qualité de l'eau interagit avec et influence les autres paramètres, parfois de manière complexe. Ce qui peut être toxique et causer la mort dans une situation peut être sans danger dans une autre.

La valeur optimale de $\mathrm{pH}$ pour cette espèce est de 7 (Viveen et al., 1985). D’autres auteurs ont signalé des $\mathrm{pH}$ variables, entre 6 et 8,5 (Institut des Standards Indien [ISI], 1974) ou 6,5 et 9,0 selon Hepher et Pruginin (1981). En définitive, $C$ gariepinus survit et se développe mieux dans des eaux dont le pH est compris entre 6 et 9. Si le pH est en dehors de cette plage, la croissance du poisson est réduite. Des valeurs inférieures à 4,5 ou supérieures à 10 entraînent des mortalités. Plus le dioxyde de carbone est éliminé de l'eau, plus son $\mathrm{pH}$ augmente. Le $\mathrm{pH}$ le plus bas de la journée est généralement associé au niveau le plus bas d'oxygène dissous. Le pH le plus élevé de la journée est généralement associé au niveau le plus élevé d'oxygène dissous. Le $\mathrm{pH}$ de l'eau est donc tributaire de la fluctuation de la quantité de dioxyde de carbone dissous.

C. gariepinus a une tolérance à des températures variant de 8 à $35^{\circ} \mathrm{C}$, bien que Teugels (1986) signale 28 à $30^{\circ} \mathrm{C}$ comme optimale pour sa croissance. La mortalité peut tout de même survenir à des températures extrêmes. Par ailleurs, la volatilité de l'oxygène augmente au fur et à mesure que la température diminue. Le niveau minimal d'oxygène dissous (OD) que le poisson peut tolérer en toute sécurité dépend de la température et, dans une certaine mesure, de l'espèce. Une exposition prolongée à des niveaux faibles et non létaux d'OD constitue un stress chronique qui entraînera l'arrêt de l'alimentation du poisson, sa capacité à transformer les aliments ingérés en chair de poisson, et à le rendre plus vulnérable aux maladies. À mesure que la quantité de dioxyde de carbone fluctue, le $\mathrm{pH}$ de l'eau change.

Clarias gariepinus s'adapte bien aux conditions environnementales extrêmes et peut résister à de faibles taux d'oxygène dissous de l'ordre de 6,5 
à 8,0 (Huisman et Richter, 1987 ; Fagbenro et Sydenham, 1988). Toutefois, Viveen et al. (1985) rapportent une valeur en oxygène dissous qui est $\geq 3 \mathrm{mg} .1^{-}$ ${ }^{1}$; oxygène dissous $\geq 3,5 \mathrm{mg} / \mathrm{l}$ (Neill et Bryan, 1991 ; Daniel, Larry, et Joseph, 2005) ; 0,001 - 0,28 mg/l (Siti-zahrah et al., 2008; Eglal et al., 2009; Mondal et al., 2010; Jiwyam, 2012; Nyanti et al., 2012 ; Gorlach-Lira et al., 2013) ; nitrite, 0,3 mg/l (Boyd, 1998) ; nitrate, 0,2 - $10 \mathrm{mg} / \mathrm{l}$ (Boyd, 1998); ammonium, 0,01 - 1,15 (Eglal et al., 2009; Zanatta et al., 2010; Mallasen et al., 2012; Nyanti et al., 2012 ; Gorlach-Lira et al., 2013). La plupart des poissons et des invertébrés d'eau douce excrètent de l'ammoniac en tant que principal déchet azoté. L'alcalinité est une mesure des ions carbonate et bicarbonate (les ions sont des atomes ou des groupes d'atomes avec une charge négative ou positive) dissous dans l'eau. La proportion d'azote ammoniacal total (TAN) qui existe sous forme ionisée et non ionisée varie avec le $\mathrm{pH}$ et la température. Lorsque le $\mathrm{pH}$ et la température augmentent, la quantité de TAN sous la forme toxique non ionisée augmente. La salinité quant à elle, affecte non seulement l'osmorégulation, mais aussi la concentration d'ammoniac non ionisé (Joseph, Soderberg, et Terlizzi, 1993). Les poissons continuellement exposés à plus de $0,02 \mathrm{ppm}$ de la forme non ionisée peuvent présenter une croissance réduite et une susceptibilité accrue aux maladies. Lorsque les poissons sont produits en élevage et nourris avec des aliments riches en protéines, ils peuvent libérer de fortes concentrations d'ammoniac dans l'eau. Les nitrites sont toxiques pour les poissons et provoquent la maladie du «sang brun ». Des concentrations de 0,5 ppm ont réduit la croissance et affecté les poissons.

\section{Régime alimentaire et besoins nutritionnels de $C$. gariepinus}

En milieu naturel, Clarias gariepinus est omnivore. Il consomme des insectes, des crabes, du plancton, des poissons, des cadavres, des plantes et des fruits (Fermon, 2011). C'est donc une espèce euryphage (Bruton, 1979) et opportuniste (Clay, 1979). Le régime alimentaire variant en fonction de la taille: les juvéniles se nourrissent dans l'ordre de préférence décroissant, d'insectes et de crustacés, de mollusques, de détritus et de plancton; les adultes et les sub-adultes, principalement de poissons (Bruton, 1979 ; Van Weerd, 1995).

En élevage, le régime alimentaire de $C$. gariepinus est composé de nauplii d'Artemia (vivants ou congelés), d'aliments artificiels de fermes fabriqués à base de sous-produits agricoles, ou d'aliments commerciaux. Ces aliments se présentent sous diverses formes allant des farines aux miettes puis aux granulés dont la taille des particules varie en fonction de la taille des poissons. La synthèse de quelques sous-produits alimentaires et autres additifs utilisables en pisciculture a été présentée par plusieurs auteurs (Yashouv et Chervinski, 1971 ; Hastings, 1973 ; Richir, 2004 ; Imorou Toko, 2007) et on 
aperçoit que la composition d'un aliment équilibré à la fois en protéines, lipides, glucides, sels minéraux et vitamines, influence grandement la croissance, la production et le comportement des poissons (Benabdellah, 2011). Les besoins en protéines et en acides aminés sont les principaux facteurs dont le déficit dans l'alimentation affecte directement la croissance du poisson (Halver, 1976). La demande en protéines des larves de $C$. gariepinus diminue de 55 à 32-28\% à partir du moment où elles ont recours à de la nourriture exogène jusqu'à un poids de $20 \mathrm{~g}$ (Hecht et al., 1988). Quant aux individus de taille allant de 10 à $1000 \mathrm{~g}$ les besoins nutritionnels en protéines brutes sont estimés à $230 \mathrm{~g}$ (Balogun et Ologhobo, 1989) voire 400 - $420 \mathrm{~g} / \mathrm{kg}$ d'aliment (Uys, 1989). Leurs besoins en glucides digestibles sont estimés à $150-350 \mathrm{~g} / \mathrm{kg}$ d'aliment (Balogun et Ologhobo, 1989; Van Weerd, 1995) tandis que les besoins en lipides sont de $110 \mathrm{~g} / \mathrm{kg}$ d'aliment (Machiels et Henken, 1987). En ce qui concerne les besoins en énergie, ils sont estimés à $13 \mathrm{kj} / \mathrm{g}$ pour l'énergie métabolisable (Machiels et Henken, 1987);12,0 kj/g pour l'énergie digestible (ED) (Hecht, Uys, et Britz, 1988) ; puis $13-17 \mathrm{kj} / \mathrm{g}$ (Van Weerd, 1995) voire 18,1 kj/g (Richir, 2004) pour l'énergie brute. Le rapport Protéines/Energie digestible a été estimé à $24 \mathrm{mg}$ de protéines/ $\mathrm{kj} \mathrm{ED}$ (Henken et al., 1986) voire 31 - 36 mg de protéines/kj ED (Degani, Ben-Zvi, et Levanon, 1989). La synthèse des besoins en vitamines, minéraux et acides aminés de cette espèce a été présentée par Richir (2004). En lien avec la température, la table de rationnement en pourcentage du poids corporel par jour de C. gariepinus selon Hogendoorn (1983) puis Hecht, Uys, et Britz (1988) est contenue dans le Tableau 1.

Tableau1 : Table de rationnement (\% du poids corporel jour $\left.{ }^{-1}\right)$ de C. gariepinus en fonction de la température $\left(T^{\circ} \mathrm{C}\right)$ (Hogendoorn, 1983 puis Hecht, Uys, et Britz, 1988).

\begin{tabular}{|l|l|l|l|l|l|l|l|l|l|l|l|l|}
\cline { 2 - 13 } \multicolumn{1}{c|}{ Poids moyen (g) } \\
\hline $\mathrm{T}{ }^{\circ} \mathrm{C}$ & 1 & 5 & $1-10$ & $\begin{array}{l}10- \\
25\end{array}$ & 25 & $\begin{array}{l}25- \\
50\end{array}$ & 50 & $\begin{array}{l}50- \\
100\end{array}$ & 100 & 200 & $\begin{array}{l}100- \\
300\end{array}$ & $\begin{array}{l}300- \\
800\end{array}$ \\
\hline 20 & 2,9 & 1,9 & 5,0 & 3,0 & 1,2 & 2,0 & 1,0 & 1,5 & 0,9 & - & 1,2 & 1,0 \\
\hline 22 & 4,4 & 3,1 & 6,8 & 4,5 & 2,2 & 3,0 & 1,9 & 2,4 & 1,6 & 1,4 & 2,0 & 1,7 \\
\hline 24 & 5,8 & 4,2 & 8,1 & 6,0 & 3,1 & 4,0 & 2,7 & 3,0 & 2,3 & 2,0 & 2,5 & 2,2 \\
\hline 26 & 7,0 & 5,1 & 9,5 & 6,6 & 3,7 & 5,1 & 3,3 & 3,6 & 2,8 & 2,5 & 3,2 & 2,8 \\
\hline 28 & 7,7 & 5,6 & 10,0 & 7,0 & 4,0 & 5,5 & 3,5 & 4,0 & 3,0 & 2,6 & 3,5 & 3,1 \\
\hline 30 & 8,0 & 5,6 & 9,8 & 6,8 & 3,9 & 5,3 & 3,4 & 3,7 & 2,9 & 2,5 & 3,2 & 2,9 \\
\hline 32 & 7,9 & 5,3 & 9,5 & 6,5 & 3,6 & 5,0 & 3,0 & 3,5 & 2,6 & - & 3,0 & 2,8 \\
\hline
\end{tabular}

Formulation, présentation des aliments de $C$. gariepinus et les contraintes

Ces contraintes sont vues globalement pour l'ensemble du secteur aquacole, et non exclusivement pour le $C$. gariepinus qui partage les mêmes ressources alimentaires que les autres espèces. Ainsi, si l'aquaculture est sans doute la meilleure alternative possible pour pallier la baisse des ressources halieutiques (Organisation des Nations Unies pour l'alimentation et l'agriculture [FAO], 2004), les poissons requièrent pour leur croissance, un 
apport élevé en protéine, rendant presque indispensable l'utilisation des matières premières d'origine animale comme la farine de poisson dans les régimes alimentaires (Guillaume et al., 1999). En général, les farines de poisson constituent la composante majeure des aliments en aquaculture : elles représentent 40 à $60 \%$ des protéines totales dans les aliments traditionnels pour les Siluridés (Van Weerd, 1995). Par ailleurs, des produits à base de soja sont utilisés en substitution à une part importante de la farine de poisson dans les aliments pour poissons, avec des avantages aux plans nutritionnel, environnemental et économique unanimement appréciés (Lim et Akinyama, 1992).

Le prix d'achat élevé de la farine de poisson (Hastings et Dickie, 1972 ; FAO, 2004), l'utilisation accrue du tourteau de soja et la disponibilité de cette source conventionnelle pour l'alimentation du poisson sont limitées par la demande croissante. Ces ressources alimentaires entrent en conflit avec l'alimentation humaine et les besoins des industries alimentaires (Siddhuraju et Becker, 2001). Toutes ces situations ont orienté la recherche vers des sources alternatives de protéines, en particulier vers celles qui ne sont pas directement utilisables pour la consommation humaine (Hoffman, Prinsloo, et Rukan, 1997; Tacon, 1996). Plusieurs auteurs (Jackson, Copper, et Matty, 1982 ; Shiau, Chuang, et Sun, 1987 ; El-Sayed, 1990; Barros, Lim, et Klesius, 2002; Azaza et al., 2006 ; Sogbesan et al., 2006 ; Tacon, Hasan, et Subasinghe, 2006) ont souligné la nécessité d'orienter les recherches sur l'utilisation de sources de protéines végétales moins chères et facilement disponibles pouvant remplacer le tourteau de soja sans réduire la qualité nutritionnelle de l'aliment. C'est pourquoi, Laporte et al. (2009) proposent de combiner les protéines animales avec d'autres ingrédients alimentaires présentant des profils d'acides aminés complémentaires afin de répondre aux besoins nutritionnels d'un large éventail d'espèces d'élevage. Les évaluations nutritionnelles indiquent que l'utilisation de tels mélanges dans les aliments des poissons pourrait aider l'industrie aquacole à devenir un fournisseur durable, écologique et éthique d'aliments de haute qualité (Glencross, Booth, et Allan, 2007).

Des sous-produits agro-industriels ou d'autres produits de substitution d'origines animales et végétales non conventionnels ont été utilisés en tant qu'ingrédients de substitution des farines et huiles de poissons dans des aliments pour C. gariepinus (Richir, 2004). Des résultats encourageants ont été obtenus pour certaines, telles que les huiles de palme et d'arachide (Orire, Omotoyinbo, et Sadiku, 2013), la farine de lentilles d'eau (Effiong, Sanni, et Fakunle, 2009), la farine de sang (Otubusin, Ogunleye, et Agbebi, 2009), la farine de têtes de crevettes (Nwanna, 2003), la farine de feuilles de manioc (Ng et Wee, 1989), orge et luzerne (Belal, 1999), les feuilles séchées de Leucaena glauca (Zamal et al., 2008), la farine de noyaux de Jatropha platyphylla (Kumar et al., 2010). Des insectes et animaux vertébrés ont été 
aussi utilisés pour la production d'aliment pour poissons (Griffin, Wilson, et Brown, 1994). Les insectes comestibles contiennent des protéines, des vitamines et des acides aminés de haute qualité (Finke, 2002). Néanmoins, l'inclusion d'insectes adultes dans le régime des poissons ne peut remplacer la farine de poisson que partiellement en raison de la présence de chitine dans leur exosquelette. $\mathrm{Ng}$ et al. (2001) ont signalé que la présence de chitine dans les exosquelettes d'insectes adultes entraînait une réduction des performances de croissance et de l'utilisation de protéines chez les poissons-chats nourris avec des niveaux élevés de ces insectes. Dans le même ordre, le problème des facteurs antinutritionnels dans les légumineuses tropicales a limité leur utilisation et leur incorporation directe dans les aliments pour animaux (Ogunji et Wirth, 2001).

En réalité, les taux d'incorporation des substituts de la farine de poisson et du tourteau de soja dans l'alimentation des poissons varient en fonction des sources protéiques de substitution et des espèces de poissons à nourrir. Chez $C$. gariepinus par exemple, ces taux sont estimés à : 4\% d'huile de Canarium schweinfurtii pour les fingerlings (Ananias, Abdullahi, et Yusuf, 2014) ; $25 \%$ à $35 \%$ de tourteaux de graines de Sesamum indicum pour les poissons omnivores et herbivores (Olukunle et Falaye, 1998 ; Tacon, 1993) ; $3 \%$ d'huile de foie de morue et $6 \%$ d'huile de palme (Ochang, Fagbenro, et Adebayo, 2007); 20\% de poudre d'arachide Arachis hypogeae pour les alevins (Dougnon, Montchowui et Gbeassor, 2015) ; 20\% de feuilles de Leucaena lecocephala (Amisah, Oteng, et Ofori, 2009) ; 20\% de graines de Leucaena lecocephala pour les alevins (Sotolu, 2010) ; 30-45\% de farine d'asticots séchés (Okore et al., 2016) voire 100\% pour les fingerlings (Ajonina et Nyambi, 2013). D'autres travaux de recherches portent sur l'utilisation en alimentation animale de ressources végétales non conventionnelles (Azolla spp, Moringa oleifera, Son de riz) et de co-produits de volaille et de poissons (Hêdji et al., 2014). La digestibilité de quelques matières premières chez $C$. gariepinus a été présentée par Ble et al. (2011), laquelle est tributaire non seulement de la méthodologie d'étude mais aussi de la qualité des ingrédients et de leur niveau d'incorporation (Abdelghany, 2003b). Néanmoins, étant donné que le coût des aliments est l'une des charges les plus élevées en aquaculture intensive et semi intensive, il est donc nécessaire de formuler des aliments pour poissons à faible coût à partir d'ingrédients disponibles localement et économiquement bénéfiques pour les pisciculteurs (Chakrabharty et al., 1973; Jafri et al., 1992). Le niveau actuel de production de poisson peut être augmenté par la formulation et la production commerciale d'aliments pour poissons en pellets qui répondent aux besoins nutritifs du poisson (Yaqoob, Ali, et Mehmood, 2010).

Techniquement, les aliments pour poissons ont été fabriqués de différentes manières, allant de poissons frais et hachés à très courte durée de 
conservation, à des aliments granulés, ou extrudés avec une teneur en eau réduite et une durée de conservation prolongée (Brown, 1977). Toutes ces techniques de production sont toujours valables, mais l'extrusion est actuellement la seule méthode permettant de fabriquer des aliments de haute performance avec une expansion suffisante permettant de contenir $40 \%$ de matières grasses (Dethlefsen, 2017). Cependant, l'un des problèmes technologiques importants qui n'est pas encore réglé dans de nombreux pays en développement est celui de la flottaison des aliments fabriqués localement. Ce qui rend la plupart des aquaculteurs africains largement dépendants des aliments pour poissons importés des pays européens pour la productivité et la durabilité de l'industrie (Projet d'Aquaculture et de Pêche Continentale [AIFP], 2004). Pour une santé optimale, une croissance rapide et une production durable des poissons d'élevage, un aliment équilibré doté de bonnes caractéristiques physiques, telles que la stabilité et la flottabilité des pellets, est nécessaire (Masser et Wurts, 1992). La plupart des espèces de poissons peuvent être formées à accepter les pellets flottants (Tacon, 1990). L'utilisation d'aliments stables et flottants aidera les poissons à leur entière valorisation et à minimiser les pertes, ce qui contribuera à une production aquacole plus rentable et durable (Wood, 1993 ; Sadiku, 1995). Les aliments flottants conviennent très bien aux animaux pélagiques ou de surface car les poissons y ont rapidement accès et ne dépensent pas beaucoup d'énergie pour nager jusqu'au fond pour se nourrir (Ballarin et Heller, 2010). En outre, bien qu'ils soient plus coûteux, il est généralement avantageux de les utiliser. Cependant, l'éleveur peut directement observer les besoins alimentaires des poissons et ajuster les taux d'alimentation en conséquence. Il pourrait ainsi déterminer si les taux d'alimentation sont trop bas ou trop élevés pour maximiser la croissance du poisson et l'efficacité d'utilisation des aliments (Chakrabharty et al., 1973 ; Jafri et al., 1992). Il est unanimement admis que les aliments aquatiques de haute qualité devraient être très stables dans l'eau pour minimiser la désintégration et la perte de nutriments lorsqu'ils sont exposés à l'eau. Sur la base de ses habitudes alimentaires prédatrices, $C$. gariepinus peut utiliser des aliments secs ou humides comme repas, des granulés coulants ou flottants, des blocs ou des miettes (Zeinhom, M. Ebrahim, et E. Ebrahim, 2010).

A ce jour, les avis restent encore partagés dans le monde scientifique sur la nécessité de la flottabilité ou non des aliments. En effet, Ajani, Dawodu, et Bello-Olusoji (2011) ont constaté une similitude dans le gain moyen de poids et la consommation quotidienne de nourriture de C. gariepinus nourri avec des aliments flottants et coulants. Aussi, Limbu (2015), constate que nourrir $C$. gariepinus avec des aliments flottants ou coulants n'affecte ni sa croissance ni le taux de survie. Par contre, Mustapha et al. (2014) ont signalé une augmentation de poids et un taux de croissance spécifique 
significativement plus élevés pour C. gariepinus nourri à base de Coppens (aliment flottant) que pour la même espèce nourrie à base d'aliment local (coulant). Ces divergences d'opinions méritent d'être élucidées.

\section{Reproduction}

\section{- Age à la première maturité sexuelle}

L'âge de maturité sexuelle de C. gariepinus varie en fonction du milieu. En milieu naturel la maturité est atteinte vers deux (02) ans (Richter, 1976), et est surtout influencée par la température, la photo périodicité, le régime alimentaire, etc. Le déclenchement final de la reproduction est provoqué par une élévation du niveau de l'eau, due aux précipitations (Ndimele et Owodeinde, 2012). Cette maturation est plus précoce en conditions d'élevage, ou $C$ gariepinus atteint sa maturité sexuelle vers sept (07) à dix (10) mois (en étang) (Viveen et al., 1985); huit (8) à dix (10) mois (Pham, 1975) ou à sept (07) mois (Legendre et al., 1992), à un poids de 100 à $200 \mathrm{~g}$ (Lazard et Legendre, 1996). C. gariepinus devient sexuellement actif, lorsqu'il atteint 40 et $45 \mathrm{~cm}$ pour les femelles et entre 35 et $40 \mathrm{~cm}$ pour les mâles (Fermon, 2011). La maturité des géniteurs n'est assurée qu'à partir d'un minimum de $22^{\circ} \mathrm{C}$, mais une température supérieure est toujours favorable au bon développement des gonades (Ducarme et Micha, 2003).

\section{* Ponte, incubation, éclosion et fécondité}

La ponte est précédée d'une parade qui dure plusieurs heures. Les couples s'isolent. Le mâle se met en U autour de la tête de la femelle. Le sperme est relâché. Pendant les mouvements de la queue de la femelle, les œufs, de couleur verdâtre, sont dispersés sur une surface importante. Après cette ponte, le couple se repose plusieurs minutes. Dans des conditions optimales d'élevage (alimentation, température, qualité et renouvellement d'eau), la fréquence minimale d'induction répétée de l'ovulation par traitement hormonal sur une même femelle est de l'ordre de six à huit semaines sans perte de la fécondité par ponte unitaire (Hogendoorn, 1983). Les œufs ont une durée d'incubation d'environ 33 heures à $25^{\circ} \mathrm{C}$; ils adhèrent finalement à la végétation submergée. En captivité, beaucoup d'œufs sont détruits par la violence des coups de queue (Richir, 2004). Ainsi, pour pallier ces pertes, ils peuvent être incubés artificiellement selon plusieurs procédés: (a) soit en suspension dans des « bouteilles de Zoug », système d'incubation conçu pour de grandes quantités d'œufs (50 g. $1^{-1}$ au maximum) où l'eau circule en permanence permettant d'éviter que les œufs ne s'agglutinent ; (b) dans un cadre grillagé en happa, cadre flottant en bois avec toile moustiquaire en plastique $(35$ x $20 \mathrm{~cm}$ à mailles de $1 \mathrm{~mm})$ pour l'incubation de $50 \mathrm{~g}$ d'œufs ; (c) ou au niveau du système racinaire de plantes aquatiques (laitue d'eau, Jacinthe d'eau, etc.), soit 3 plantes de Jacinthe d'eau «Eichornia crassipes » pour $50 \mathrm{~g}$ d'œufs; (d) ou encore dans des paniers recouverts de toile 
moustiquaire (Rukera Tabaro, Micha, et Ducarme, 2005 ; Imorou Toko, 2007).

Après la fraie, le banc de poissons-chats retourne en eau plus profonde. Quelques semaines plus tard, C. gariepinus produit à nouveau un groupe d'œufs et se prépare à une nouvelle fraie (reproduction). Une seconde fraie sera provoquée par les pluies ou par une nouvelle crue. Plusieurs fraies peuvent se succéder dans la même année (Pillay, 1990). Les œufs éclosent après 24 à 36 heures, suivant la température de l'eau (Viveen et al., 1985). Appelées à cette phase larves vésiculées, le stade larvaire est assez prolongé allant de 11 à 15 jours avec une alimentation particulière (Fermon, 2011 ; Hecht, 1996). Les alevins et les juvéniles de poisson-chat africain sont difficiles à trouver dans la nature. C'est probablement dû à la forte mortalité des œufs et des larves. Il n'y a pas de soins parentaux si ce n'est le choix du site de ponte. Le développement des œufs et des larves est rapide et les jeunes sont en nage libre 48 à 72 heures après la fécondation. Les jeunes restent dans les zones inondées et vont migrer quand ils atteignent 1,5 à 2,5 cm de long (Fermon, 2011). L'indice gonado-somatique (IGS) des poissons-chats africains mâles n'excède pas $1 \%$, et la concentration en spermatozoïdes de leur semence est de $10^{9} \mathrm{spz} \cdot \mathrm{ml}^{-1}$ (Legendre, Linhart, et Billard, 1996). Les ovaires des femelles contiennent avant la fraie, des ovogonies et des ovocytes à différents stades de développement (Legendre et al., 1992).

La fécondité absolue (nombre total d'ovules pondus avant la fécondation ou d'œufs émis par une femelle) chez les poissons augmente avec la taille des femelles. Chez C. gariepinus, la fécondité absolue est de 39.000 œufs pour une femelle de $500 \mathrm{~g}$. Des valeurs de 81.000 œufs et 132.600 œufs ont été rapportées respectivement pour des femelles de $1 \mathrm{~kg}$ et $1,5 \mathrm{~kg}$ (Hogendoorn, 1983). Par ailleurs, une fécondité absolue allant de 50.000 à 200.000 œufs par ponte a été rapportée pour une femelle de taille comprise entre 40 et $50 \mathrm{~cm}$ (Hecht, 1996). Une corrélation hautement significative s'observe entre la taille de la femelle et sa fécondité qui est reliée exponentiellement à la longueur $(\mathrm{mm})$ et linéairement aux poids $(\mathrm{g})$. Quant à la fécondité relative (nombre d'œufs ou d'ovules par unité de poids vif) la moyenne de cette espèce oscille entre 20.000 et 25.000 œufs par kilogramme. C. gariepinus est caractérisé par un IGS (indice gonado-somatique) allant de 15 à $20 \%$, une fécondité de 30.000 à 150.000 œufs par $\mathrm{kg}$, un diamètre des ovules compris entre 1,2 et 1,5 mm (Hogendoorn, 1979 ; Richter et al., 1987 ; Legendre et al., 1992 ; Bruton, 1996) ou 1,4 et 1,6 mm (Viveen et al., 1985 ; de Graaf et Janssen, 1996 ; Gilles, Dugué, et Slembrouk, 2001). Selon Lagler (1971), l'indice gonado-somatique est le poids des gonades (Pgo) en \% du poids corporel $(\mathrm{Pt})$. Il est donné par la formule : $I G S(\%)=[\operatorname{Pgo}(g) / P t(g)] x$ 100. 


\section{* Contrôle de la reproduction et Hybridation}

La reproduction sans aucun recours à l'induction hormonale de l'ovulation est possible chez $C$. gariepinus, mais elle donne des résultats médiocres en termes de nombre d'œufs et d'alevins produits. En étang où l'on simule une crue (remplissage de l'étang en une journée), elle conduit à une production d'alevins de l'ordre de 145 individus par $100 \mathrm{~m}^{2}, 1,5$ mois après l'empoissonnement en géniteurs sexuellement matures (Lazard et Legendre, 1996).

La méthode de reproduction la plus efficace chez $C$. gariepinus est la reproduction artificielle caractérisée par trois principales étapes que sont : le choix des géniteurs basé sur des critères externes, l'induction hormonale de la ponte et l'incubation (Rukera Tabaro, Micha, et Ducarme, 2005). Pour le choix judicieux des géniteurs, on repère les bonnes femelles reproductrices les plus matures, par la rondeur de l'abdomen bien gonflé et dilaté qui sous légère pression émet quelques ovules. Pour les mâles, il convient de prendre les plus gros, ce qui signifie très souvent que leurs testicules sont bien développés et pleins de sperme laiteux (Ducarme et Micha, 2003 ; Rukera Tabaro, Micha, et Ducarme, 2005). La reproduction avec traitement hormonal comprend le choix de l'hormone et la dose à injecter aux femelles matures, le stripping (collecte des œufs par pression abdominale manuelle), la fécondation in vitro et l'incubation des œufs. Différentes hormones sont couramment utilisées en intramusculaire ou en sous-cutané pour induire la maturation finale ou l'ovulation chez Clarias gariepinus (Imorou Toko, 2007) : ce sont le HCG (Human Chorionic Gonadotropin : 25 UI 100 ${ }^{-1}$ de femelle), la LH (Luteining Hormon : 0,5 ml kg-1 de femelle), le DOCA (Desoxycorticosteroïd Acetate : 2,5-5 mg $100 \mathrm{~g}^{-1}$ de femelle) ou Ovaprim ${ }^{\circledR}($ LH-RHa + antagoniste de la dopamine : $0,5 \mathrm{ml} \mathrm{kg}^{-1}$ de femelle), le progestatif, la pimozide. Otémé, Hem, et Legendre (1996) ont obtenu 100\% d'ovulation après une seule injection intramusculaire de HCG à la dose optimale de $1,5 \mathrm{UI} \mathrm{g}^{-1}$ de femelle. Cependant, dans certaines conditions, l'utilisation de suspensions hypophysaires de carpe, de poissons-chats, de tilapia ou de grenouille est pourtant préférée (Nwadukwe, 1993 ; Nwadukwe, Ayinla, et Abby-Kalio, 1993 ; de Graaf et Janssen, 1996 ; Ducarme et Micha, 2003 ; Adebayo et Fagbenro, 2004; Nwokoye, Nwuba, et Eyo, 2007). Les mâles sont toujours abattus afin de prélever leurs testicules qui sont ensuite broyés pour récupérer la laitance que l'on conserve à sec dans des seringues de 5 à $10 \mathrm{ml}$ maintenues au froid sur un lit de glace jusqu'à la fécondation (Ducarme et Micha, 2003). Onze à quinze heures après l'injection (à environ $28^{\circ} \mathrm{C}$ ) des femelles, les ovules arrivent à maturité (Nguenga et al., 1996). Elles sont ensuite anesthésiées (Quinaldine), strippées et les ovules récupérés à sec ( 30.000 ovules/kg de femelle) dans une bassine en plastique. On mélange ensuite la laitance aux ovules puis par addition d'eau, on provoque la fécondation. Après 
avoir mélangé le tout délicatement pendant 5 minutes, on rince au moins 3 fois pour éliminer l'excédent de sperme et les débris de tissus gonadiques (Ducarme et Micha, 2003). Chez C. gariepinus, aucune référence relative à l'âge recommandé pour la réforme des géniteurs ne semble exister (Lazard et Legendre, 1996).

L'hybridation ou croisement est possible par le biais de fécondations in vitro (Legendre et al., 1992). Par exemple, l'hybride (H. longifilis x $C$. gariepinus) exprime une croissance équivalente ou supérieure à celle du parent le plus performant $(H$. longifilis), en fonction des conditions environnementales. Le sexe ratio des hybrides est équilibré ; ils sont fertiles mais avec une mauvaise efficacité de leur gamétogénèse.

\section{Croissance}

Pillay (1990) rapporte un poids moyen d'environ $10 \mathrm{~g}$ en trois semaines de larves élevées à base d'aliment vivant à une densité de 10.000 à 20.000 individus par hectare. Les taux de croissance optimaux semblent cependant être atteints avec une combinaison d'aliment artificiel et de nourriture vivante (Hecht, 1996 ; Uys et Hecht, 1985). La température par ailleurs a une influence importante sur les premiers stades de développement de $C$. gariepinus comme rapportée dans le Tableau 2 (Haylor et Mollah, 1995).

Tableau 2 : Influence de la température sur les premiers stades de développement de $C$. gariepinus (Haylor et Mollah, 1995).

\begin{tabular}{|c|c|c|c|c|c|c|c|c|c|}
\hline Température $\left({ }^{\circ} \mathbf{C}\right)$ & 20 & 22 & 24 & 26 & 28 & 30 & 32 & 34 & 35 \\
\hline \multicolumn{10}{|l|}{$\begin{array}{l}\text { Temps } \quad \text { (jours) } \\
\text { pour : }\end{array}$} \\
\hline 1. Eclosion & 2,36 & 1,73 & 1,37 & 1,13 & 0,96 & 0,84 & 0,74 & 0,67 & 0,63 \\
\hline $\begin{array}{l}\text { 2.Première } \\
\text { alimentation }\end{array}$ & 4,78 & 3,51 & 2,77 & 2,29 & 1,95 & 1,70 & 1,50 & 1,35 & 1,28 \\
\hline $\begin{array}{l}\text { 3. Résorption du } \\
\text { sac vitellin }\end{array}$ & 6,49 & 4,76 & 3,76 & 3,10 & 2,64 & 2,30 & 2,04 & 1,83 & 1,74 \\
\hline
\end{tabular}

Les juvéniles de $C$. gariepinus ont des taux de croissance spécifique et de conversion alimentaire comparables à ceux d'autres espèces de poissons. Pour des niveaux d'alimentation optimaux, le taux de croissance spécifique (SGR) de cette espèce diminue de $12 \%$ par jour pour les juvéniles $(0,3-14 \mathrm{~g})$ à moins de $2 \%$ par jour pour les adultes (200-300 g), alors que le taux de conversion alimentaire augmente de 0,7 pour les juvéniles à 1,5 pour des adultes. Les taux de croissance spécifique et de conversion alimentaire de $C$. gariepinus au taux optimal d'alimentation ont été synthétisés dans le Tableau 3 pour différents intervalles de poids corporel (Van Weerd, 1995 in Richir, 2004). 
Tableau 3 : Taux de croissance spécifique (SGR) et taux de conversion alimentaire $(F C)$ au taux optimal d'alimentation (FL), en \% de leur poids corporel par jour, différentes températures pour différents intervalles de poids corporel de C. gariepinus (Van Weerd, 1995).

\begin{tabular}{|c|c|c|c|c|c|}
\hline $\begin{array}{l}\text { Intervalles } \\
\text { de poids } \\
\text { corporel } \\
\text { (g) }\end{array}$ & $\begin{array}{l}\text { SGR } \\
(\% / \text { jour })\end{array}$ & $\begin{array}{l}\text { FC } \\
(g / g)\end{array}$ & $\begin{array}{l}\text { FL } \\
\text { (\%/jour) }\end{array}$ & $\begin{array}{l}\text { Température } \\
\left({ }^{\circ} \mathbf{C}\right)\end{array}$ & Référence \\
\hline $0,3-3$ & 11 & 1,2 & 10 & 30 & $\begin{array}{l}\text { Hogendoorn et al., } \\
1983\end{array}$ \\
\hline $0,5-10$ & $8-12$ & $0,7-1,4$ & 10 & 30 & Hogendoorn, 1981 \\
\hline $1-1,4$ & $9-12$ & $0,6-0,9$ & - & $26-34$ & Uys, 1989 \\
\hline $3,5-21,5$ & 1,7 & 0,94 & 4 & 27 & $\begin{array}{l}\text { Degani, Ben-Zvi, } \\
\text { et Levanon, } 1989 \\
\text { Conceiçao, }\end{array}$ \\
\hline $\mathbf{0 , 8 - 3 7 , 7}$ & $2,4-8,6$ & - & $6,2-51,5$ & 28 & $\begin{array}{ll}\text { Derjant, } & \text { et } \\
\text { Verreth, } 1998\end{array}$ \\
\hline $9-36$ & $5-7$ & $0,8-1,0$ & - & $26-34$ & Uys, 1989 \\
\hline $5-40$ & 6 & 1,6 & 5 & 30 & $\begin{array}{l}\text { Hogendoorn et al., } \\
1983\end{array}$ \\
\hline 17-49 & $3-5$ & $0,7-1,0$ & - & $26-34$ & Uys, 1989 \\
\hline $25-70$ & 4 & 1,6 & 4 & 30 & $\begin{array}{l}\text { Hogendoorn et al., } \\
1983\end{array}$ \\
\hline $5-150$ & 3,7 & - & ad libitum & - & Wedekind, 1991 \\
\hline $5-170$ & 3,9 & - & ad libitum & - & Wedekind, 1991 \\
\hline $95-200$ & 2 & 3,0 & 1,5 & 25 & $\begin{array}{l}\text { Hogendoorn et al., } \\
1983\end{array}$ \\
\hline $5-220$ & 4,2 & - & ad libitum & - & Wedekind, 1991 \\
\hline $160-303$ & $1,3-3,1$ & $\begin{array}{l}1,17- \\
2,01\end{array}$ & - & $26-34$ & Uys, 1989 \\
\hline $5-320$ & 4,5 & - & ad libitum & - & Wedekind, 1991 \\
\hline $10-340$ & 1,9 & 0,93 & 4 & 27 & $\begin{array}{l}\text { Degani, Ben-Zvi, } \\
\text { et Levanon, } 1989\end{array}$ \\
\hline
\end{tabular}

Certains auteurs ont rapporté l'existence de variations dans la taille des fingerlings produits à partir du même stock géniteur de clariidés au même moment, qui pourraient être liées à la taille des œufs (Ayinla et Nwadukwe, 1989). Selon Viveen et al. (1985), les fingerlings désignent les individus dont la longueur totale varie de 3 à $10,0 \mathrm{~cm}$ et le poids corporel de 1 à $10 \mathrm{~g}$ (Tableau 4), alors qu'en général ce terme sans définition rigoureuse ni rigide, se définit comme des petits poissons de la taille d'un doigt humain. Par ailleurs, d'autres auteurs ont souligné l'importance de la densité de stockage et son influence sur l'ingestion alimentaire, la conversion alimentaire, le poids corporel, le taux de croissance spécifique, la survie et surtout la croissance des poissons (Ellis et al., 2002 ; Jamabo et Keremah, 2009 ; Dasuki, Auta, et Oniye, 2013). En effet, pour les densités d'élevage de $5,10,15,20$, et 25 alevins/litre, la croissance et la survie optimales de C. gariepinus ont été obtenues aux densités 
de 5, 10 et 15 alevins/litre d'eau. Cependant, la densité optimum d'élevage a été fixée à 15 alevins/litre d'eau. Il ressort qu'à faible densité d'élevage, les alevins se sont bien alimentés et ont converti au maximum l'aliment ingéré en biomasse. De plus la mortalité a été plus élevée au niveau des fortes densités puis souvent, les individus morts retirés des bassins étaient relativement de petites tailles avec un abdomen aplati, signe d'un estomac vide. Il est donc concevable que les plus petits individus n'aient pas eu accès à l'aliment, car ne pouvant pas entrer en compétition avec leurs congénères plus grands. L'effet de la densité de stockage sur la survie des alevins dépend de l'espèce (Nwipie, Erondu, et Zabbey, 2015). Par ailleurs, à partir d'un poids moyen initial de $32 \mathrm{~g}$, des poids moyens finaux et taux de survie de $346 \mathrm{~g}$ et $85 \%$ puis $385 \mathrm{~g}$ et $95 \%$ ont été obtenus pour C. gariepinus en cage flottante en 8 semaines pour les densités d'élevage respectives de 200 individus $/ \mathrm{m}^{3}$ et 50 individus $/ \mathrm{m}^{3}$ (Hengsawat, Ward, et Jarutjaramom, 1997). Toutefois, une densité de stockage de 50 poissons $/ \mathrm{m}^{3}$ a été recommandée par Dasuki, Auta, et Oniye (2013) pour un rendement optimal. En effet, 300 individus de poids vif total $1,8 \mathrm{~kg}$ ont été stockés dans des cages en bambou aux densités de 25 , 50 et 75 poissons $/ \mathrm{m}^{3}$, les poids moyens initiaux étaient respectivement de $5,6 \pm 0,23 \mathrm{~g}, 5,9 \pm 0,23 \mathrm{~g}$ et $6,3 \pm 0,23 \mathrm{~g} / \mathrm{m}^{3}$. Au terme de 150 jours d'élevage, les résultats obtenus dans l'ordre croissant des densités étaient : pour le poids moyen final $(828,0 \pm 1,83 \mathrm{~g} ; 774,0 \pm 20,18 \mathrm{~g}$ et $693,0 \pm 34,20 \mathrm{~g})$, taux de croissance spécifique $(3,33 ; 3,25$ et 3,43$)$, le taux de conversion alimentaire $(4,99 ; 4,73$ et 3,43$)$ et le taux de survie $(99,84 ; 99,66$ et 99,50). Les résultats ont révélé une influence significative $(\mathrm{P}<0,05)$ de la densité de stockage sur la croissance et les taux de survie de $C$. gariepinus. Les poissons stockés à très forte densité ont présenté la plus faible croissance et le taux de survie le plus bas. La meilleure production avec un poids total final de $38,67 \mathrm{~kg}$ et un indice de profit de 3,27 a été obtenue dans les cages ayant abrité les poissons à 50 individus $/ \mathrm{m}^{3}$, en comparaison aux autres traitements.

Tableau 4 : Dénominations de Clarias gariepinus en fonction de la taille et du poids corporel (Viveen et al., 1985)

\begin{tabular}{lll}
\hline Dénominations & Taille & Poids corporel \\
\hline CEufs & $1-1,6 \mathrm{~mm}$ & $1,2-1,8 \mathrm{mg}$ \\
Larves & $5-7,0 \mathrm{~mm}$ & $1,8-3 \mathrm{mg}$ \\
Alevins & $8-30,0 \mathrm{~mm}$ & $3,0-1000 \mathrm{mg}$ \\
Fingerlings & $3-10,0 \mathrm{~cm}$ & $1-10 \mathrm{~g}$ \\
Poissons adultes & $32-140 \mathrm{~cm}$ & $0,3-16 \mathrm{~kg}$ \\
\hline
\end{tabular}

En fonction du mode d'alimentation, de la durée d'élevage, de la densité de stockage, du dispositif et du système d'élevage, différentes valeurs de gain moyen quotidien (GMQ) et de poids ont été rapportées pour $C$. gariepinus non hybridé, à raison de 3,2 g/j (Dasuki, Auta, et Oniye, 2013); 3,3 $\mathrm{g} / \mathrm{j}$ en polyculture en cage (Otubusin, 1997) ; 4,2 $\mathrm{g} / \mathrm{j}$ en cage (Otubusin et 
Olaitan, 2001) ; 7,3 g/j (Otubusin, Olaofe, et Agbebi, 2004). Un GMQ de 2,6 $\mathrm{g} / \mathrm{j}$ a néanmoins été rapporté pour des hybrides de $C$. gariepinus élevés en monoculture en bassin en béton (Salami, Fagbenro, et Sydenham, 1993). Globalement, $C$. gariepinus présente un taux de croissance intéressant, atteignant 500 à $1000 \mathrm{~g}$ en 8 mois (Fermon, 2011). Toutefois, la durée du cycle de grossissement dépend de la taille du poisson requise par le marché. A des températures comprises entre 26 et $28^{\circ} \mathrm{C}$, le poisson peut croître de 1 à $800 \mathrm{~g}$ en sept mois (Dasuki, Auta, et Oniye, 2013). Il peut atteindre des tailles maximales variables dans la nature de $1,7 \mathrm{~m}$ à $2 \mathrm{~m}$ (Froese et Daniel, 2011 ; Okore et al., 2016) pour la longueur totale. Par ailleurs un poids vif record de $58,9 \mathrm{~kg}$ a été indiqué par Hecht (1996) puis Okore et al. (2016), pouvant atteindre $60 \mathrm{~kg}$ (Fermon, 2011). Les mâles et femelles des hybrides $(H$. longifilis x C. gariepinus) ont une croissance équivalente (Lazard et Legendre, 1996).

\section{Systèmes et dispositifs d'élevage de $C$. gariepinus}

La classification des systèmes de pisciculture est en fonction de l'origine de l'aliment utilisé, du degré d'alimentation et du degré d'intensification. Considérant la typologie basée sur l'origine de l'aliment d'élevage, on distingue les piscicultures de production et celles de transformation. Les piscicultures de production regroupent les systèmes où l'aliment a pour origine essentielle (ou unique), l'écosystème. C'est le cas de l'écosystème étang. La gestion dans ce cas fait appel à la fertilisation ou à l'alimentation complémentaire, ainsi qu'à la mise en œuvre de la polyculture. Les piscicultures de transformation quant à elles regroupent les systèmes où le poisson se nourrit d'aliments artificiels, généralement sous forme de granulés et comportant une proportion parfois très élevée de farine de poisson (Dabbadie, Lazard, et Oswald, 2002).

Une autre classification peut être établie, suivant la typologie basée sur le degré d'intensification et les pratiques d'alimentation. Ainsi, classiquement on distingue les systèmes de production piscicole extensifs, les systèmes semiintensifs, et les systèmes intensifs et super intensifs. Les systèmes de production piscicole extensifs, basés sur la productivité naturelle de l'environnement ou de la structure d'élevage des poissons, sans ou avec très peu d'apports d'intrants. Les systèmes d'intégration entre riziculture et pisciculture (rizipisciculture) appartiennent à cette catégorie extensive, puisque le poisson bénéficie des intrants apportés pour la culture du riz. Les systèmes de production piscicole semi-intensifs, quant à eux, reposent sur l'utilisation d'une fertilisation ou sur l'emploi d'une alimentation complémentaire, sachant qu'une part importante de l'alimentation du poisson est fournie in situ par l'aliment naturel. Les élevages associés, du type volaillepoisson ou porc-poisson appartiennent typiquement à ce système de 
pisciculture, ainsi que tous les systèmes piscicoles recyclant différents types de déchets, notamment les systèmes de recyclage direct (étangs à latrines du Vietnam par exemple). Enfin, les systèmes intensifs et super intensifs, dans lesquels tous les besoins nutritionnels des poissons sont satisfaits par l'apport exogène d'aliments complets, avec pas ou très peu d'apports nutritionnels issus de la productivité naturelle du bassin ou du plan d'eau dans lequel le poisson est élevé (lac, rivière). Ces systèmes sont par conséquent coûteux, l'aliment utilisé est généralement riche en protéines (25 à $40 \%$ ) et les principales infrastructures d'élevage sont les enclos, les cages ou les raceways, avec des taux de renouvellement de l'eau très élevés (Dabbadie, Lazard, et Oswald, 2002). Par ailleurs, les poissons peuvent être élevés en monoculture ou polyculture (Bard et al., 1974 ; Legros, 1998 ; Richir, 2004 ; Hecht, 2013). Chaque système d'élevage s'adapte à l'environnement dans lequel il doit s'intégrer et présente des avantages et des inconvénients qui peuvent influencer son choix. Dans tous les cas, la technicité constitue la condition de base à une bonne mise en œuvre des différents modèles d'élevage (Legendre et Lévêque, 1999). L'utilisation d'infrastructures, d'installations dans un système d'aquaculture, qui permettent d'assurer un meilleur environnement possible, une alimentation et une croissance optimale, une bonne santé et un bien-être des poissons, mais également pour prévenir contre des pathologies, constituent ce qu'on appelle les dispositifs d'élevage (Beveridge, 1996 ; Naylor et al., 2000; Oluwashina et Solomon, 2012). Ces dispositifs d'élevage varient suivant les systèmes d'aquaculture et comprennent : les étangs, les bassins en béton, les raceways, les cages flottantes, les enclos, les casiers de rizipisciculture.

\section{Maladies des poissons}

Dans l'eau, les agents pathogènes se transmettent facilement d'un poisson à l'autre par la peau et les branchies. Le poisson-chat africain, sensible au stress, peut être dérangé par une mauvaise qualité de l'eau, un mauvais régime alimentaire, des manipulations trop rudes ou un environnement troublé. Il peut en résulter une diminution d'activité du système immunitaire, ce qui peut provoquer l'apparition subite d'une maladie. Les alevins et les juvéniles sont les plus vulnérables ; ils doivent développer leur immunité. Les poissons stressés peuvent souvent se reconnaître à un comportement anormal, tel qu'une diminution de l'appétit, une nage nerveuse ou en se dandinant, une position verticale à la surface, ou par des symptômes cliniques ou pathologies telles que les anomalies morphologiques (barbillons ou des nageoires abîmés, gros ventre, bouche bloquée, goitres, etc.), les troubles oculaires (yeux protubérants, œil vitreux, perte de l'œil, etc.), troubles branchiaux (dégénérescence, points blancs, etc.), troubles des organes internes (taches sombres sur le foie, cœur, rate; inflammations de l'intestin ; etc.), troubles 
cutanés (mousses aux lèvres, tumeurs noirâtres, etc.), troubles du comportement (les poissons pipent l'air en surface, mouvements natatoires non coordonnés, etc.), hôtes indésirables (algues, hydres, eau chlorée, etc.). Néanmoins, ces symptômes ne sont pas spécifiques, par conséquent, des techniques de laboratoire précises sont nécessaires pour diagnostiquer la maladie. Il est toutefois important de bien inspecter les structures d'élevage tous les jours, en particulier lors du nourrissage, lorsque le poisson-chat vient à la surface de l'eau. En cas de doute, il faudra prendre le poisson vivant pour l'examiner. Pour diagnostiquer les maladies bactériennes, fongiques ou parasitaires, il faut examiner des préparations de fragments de peau, de filaments branchiaux ou d'intestins. Pour l'identification d'une maladie, il faut utiliser un microscope à grossissement : x 40 et x 100 . Une fois le diagnostic d'une maladie établi, on peut commencer un traitement spécifique. Il existe une multitude d'affections possibles (parasitaires, bactériennes, virales, etc.); elles font l'objet d'ouvrage très détaillé par Lacroix (2004).

\section{Conclusion}

Clarias gariepinus est une espèce de poisson rustique, capable de survivre dans un environnement extrême. Cependant sa croissance est affectée négativement au-delà d'une certaine limite. Dans les systèmes de production, la reproduction artificielle de cette espèce avec induction hormonale de l'ovulation est la plus recommandée dans le but d'une production massive, continue et régulière. Mais la principale contrainte liée à cette forme de reproduction pour les petits producteurs est le coût élevé des hormones commerciales. Toutefois l'utilisation des glandes pituitaires de la même espèce et de carpes par exemple, a donné des résultats très encourageants. En outre, la non disponibilité d'aliment local efficace et efficient en substitution aux aliments commerciaux importés qui coûtent chers, constitue aussi un frein à l'essor de la production de cette espèce. Les performances de croissance de C. gariepinus varient en fonction du système d'élevage et du dispositif d'élevage. Pour une aquaculture durable, il est nécessaire d'utiliser des infrastructures et des techniques de production performantes.

\section{References:}

1. Abdelghany, A. E. (2003b). Partial and complete replacement of fish meal with Gambia meal in diets for red tilapia Oreochromis niloticus x O. mossambicus. Aquaculture Nutrition, 3, 145-154.

2. Adebayo, O. T. \& Fagbenro, O. A. (2004). Induced ovulation and spawning of pond raised African giant catfish, Heterobranchus bidorsalis by exogenous hormones. Aquaculture, 242, 229-236.

3. Ahotondji, A. (2012). Renforcement des capacités nationales des petits producteurs dans la production intensive d'alevins de clarias. 
Rapport Technique Définitif. Projet ACP FISH II, Activité 4.1, Projet $\mathrm{N}^{\circ}$ :A8bDOI:acpfish2eu.org/.../RTF\%20Projet\%20A8\%20ACP\%20F ISH\%20II\%20G, 28.

4. Ajani, F., Dawodu, M. \& Bello-Olusoji, O. (2011). Effects of feed forms and feeding frequency on growth performance and nutrient utilization of Clarias gariepinus fingerlings. African Journal of Agricultural Research, 6(2), 318-322.

5. Ajonina, A. S. \& Nyambi R. E. (2013). Evaluation of growth response of Clarias gariepinus fingerling fed dried maggot as protein source. International Journal of Current Microbiology and Applied Sciences, 2(5), 123-129.

6. Amisah, S., Oteng, M. A. \& Ofori J. K. (2009). Growth performance of the African catfish, Clarias gariepinus, fed varying inclusion levels of Leucaena leucocephala leaf meal. Journal of Applied Science and Environmental Management, 13(1), 21 - 26.

7. Ananias, T. Y., Abdullahi, O. M. \& Yusuf, G. A. (2014). Growth Performance and Body Composition of Clarias gariepinus Fingerlings Fed Varying inclusion Level of Canarium schweinfurtii (African Elemi) Oil. International Conference on Advances in Agricultural, Biological \& Environmental Sciences. Dubai (UAE), 4. http://dx.doi.org/10.15242/IICBE.C1014156.

8. Anusuya Devi, P., Padmavathy, P., Aanand, S. \& Aruljothi, K. (2017). Review on water quality parameters in freshwater cage fish culture. International of Applied Research, 3(5), 114- 120.

9. Aquaculture and Inland Fisheries Project (AIFP) (2004). Inventory of fish farms in Nigeria. Technical report. Published by Aquaculture and Inland Fisheries Project. Annex II of the National Special Program for Food Security with the Aquaculture Development Program in all states and FCT Abuja, Nigeria, 1-8.

10. Arulampalam, P., Yusoff, F. M., Law, A. T. \& Rao, P. S. S. (1998). Water quality and bacterial populations in a tropical marine cage culture farm. Aquaculture Research, 29, 617-624.

11. Ayinla, O. A. \& Nwadukwe, F. O. (1989). Fingerlings size variation among freshwater catfish: Effect of broodstock sizes. In: A. O. Onyia \& G. N. Ajana (Eds.), Fish for food: Meeting the demand. Proceeding of a Conference, 13-17 November 1989, 43-47. Fisheries Society of Nigeria.

12. Azaza, M. S., Mensi, F., Imorou Toko, I., Dhraief, A., Abdelmouleh, A., Brini, B. \& Kraïem, M. M. (2006). Effets de l'incorporation de la farine de tomate dans l'alimentation du tilapia du nil (Oreochromis niloticus, L., 1758) en élevage dans les eaux géothermales du sud 
tunisien. Bulletin de l'Institut National des Sciences et Technologies de la Mer de salammbô, 33, 16.

13. Ballarin, A. M. \& Heller, Lo. (2010). Evaluation of yam starch (Discorea rotundata) as aquatic feed binder. Pakistan Journal of Nutrition, 9(7), 668-671.

14. Balogun, A. M. \& Ologhobo, A. D. (1989). Growth performance and nutrient utilization of fingerling Clarias gariepinus (Burchell) fed raw and coocked soybean diets. Aquaculture, 76, 119-126.

15. Baras, E. \& Lalèyè, P. (2003). Ecology and behaviour of catfishes, Chapter 18. In G. Arratia, B. G. Kapoor, M. Chardon, \& R. Diogo (Eds sc.), Catfishes, 525-579. Science Publishers (2), Inc; Enfield, NH (USA).

16. Bard, J., de Kimpe, P., Lemasson, J. \& Lessent, P. (1974). Manuel de pisciculture tropicale. Nogent-sur-Marne, 209.

17. Barros, M. M., Lim, C. \& Klesius, P. H. (2002). Effect of soybean meal replacement by cottonseed meal and iron supplementation on growth, immune response and resistance of channel catfish (Ictaturus puctatus) to Edwarsiella ictaluri challenge. Aquaculture, 207, 263-279.

18. Belal, I. E. H. (1999). Replacing dietary corn with barley seeds in Nile tilapia Oreochromis niloticus (L.) feed. Aquaculture Research, 30, 265-269.

19. Benabdellah, N. (2011). Etude expérimentale sur l'activité des enzymes digestives (trypsine et chymotrypsine) chez les alevins du tilapia du Nil (Oreochromis niloticus) (Linnaeus, 1758 en relation avec la qualité du régime alimentaire protéique distribué. Mémoire pour l'obtention du diplôme de Magister, Faculté des Sciences de l'université d'Oran, 94.

20. Beveridge, M.C.M. (1996). Cage Aquaculture. Second Edition. Oxford: Fishing News, Oxford, 346.

21. Ble, M. C., Otchoumou, K. A., Alla, Y. L. \& Kaushik, S. J. (2011). Utilisation des farines végétales dans l'alimentation des poissons d'élevage en milieu tropical. Fiches techniques \& Documents de Vulgarisation, 7-11.

22. Boyd, C. E. (1998). Water quality for pond aquaculture. Research and Development Series No.43. International center for Aquaculture and Aquatic Environments, Alabama Agricultural Experiment Station, Auburn University, Alabama. 37.

23. Brown, E. E. (1977). World fish farming: Cultivation and Economics. AVI Publishing Company, Connecticut, USA, 397.

24. Bruton, M. N. (1979). The breeding biology and early development of Clarias gariepinus (Pisces: Clariidae) in lake Sibaya, South Africa, 
with a review of breeding in species of the subgenus Clarias. Transactions of the Zoological Society of London, 35, 1-45.

25. Bruton, M. N. (1996). Alternative life-history strategies of catfishes. Aquatic Living Resources, 9, 35-41.

26. Chakrabharty, R. D., Murthy, D. S., Sen, P. R. \& Chatterjee, D. K. (1973). Preliminary observations in the usefulness of silkworm pupae feed for fingerling of Indian major carps and common carp. Journal of the Inland Fisheries Society of India, 3, 117-118.

27. Clay, D. (1979). Population biology, growth and feeding of African catfish (Clarias gariepinus) with special reference to juveniles and their importance in fish culture. Archiv fur Hydrobiology, 87 (4), 453482.

28. Conceiçao, L. E. C., Dersjant-Li, Y. \& Verreth, J. A. J. (1998). Cost of growth in larval and juvenile African catfish (Clarias gariepinus) in relation to growth rate, food intake and oxygen consumption. Aquaculture, 161, 95-106.

29. Coppens (2012). Aliments pour clarias. 21p. (disponible sur www.coppens.eu).

30. Dabbadie, L., Lazard, J. \& Oswald, M. (2002). La pisciculture et les élevages non conventionnels. In CIRAD \& GRET (Eds.), Memento de l'agronome, 1571-1615. Jouve, 11, bd of Sébastopol, 75001 PARIS.

31. Daniel, S., Larry, W. D. \& Joseph, H. S. (2005). Comparative oxygen consumption and metabolism of striped bass (Morone saxatilis) and its hybrid. Journal of World Aquaculture Society; 36(4), 521-529.

32. Das, A. B. \& Ratha, B. K. (1996). Physiological adaptive mechanisms of catfish (Siluroidei) to environmental changes. Aquatic Living Resources, 9, 135-143.

33. Dasuki, A., Auta, J. \& Oniye, S. J. (2013). Effect of stocking density on production of Clarias gariepinus (Tuegels) in floating bamboo cages at kubanni reservior, Zaria, Nigeria. Bayero Journal of Pure and Applied Sciences, 6(1), $112-117$.

34. Degani, G., Ben-Zvi, Y. \& Levanon, D. (1989). The effect of different protein levels and temperatures on feed utilization, growth and body composition of Clarias gariepinus (Burchell 1822). Aquaculture, 76, 293-301.

35. de Graaf, G. \& Janssen J. (1996). Handbook on the artificial reproduction and pond rearing of the African catfish Clarias gariepinus in sub-Saharan Africa. FAO, Fisheries technical paper, Rome, 362.

36. Dethlefsen, M. W. (2017). Die Hard - improving the physical quality of extruded fish feed pellets. PhD thesis. Kgs. Lyngby: National Food Institute, Technical University of Denmark, 81. 
37. Diallo, A. \& Thiam, N. (2010). Module de formation des formateurs sur le suivi des poissons d'eau douce. Intégration de la biodiversité d'eau douce dans le processus de développement en Afrique. Projet de démonstration bassin du fleuve Gambie; Wetlands International Afrique, DAKAR-FANN, 43.

38. Dougnon, T. J., Montchowui, E. \& Gbeassor, M. (2015). Effect of peanut powder (Arachis hypogeae L., 1753) on zootechnic parameters and sex inversion in catfish Clarias gariepinus. Indian J Physiol Pharmacol; 59(1), 78-86.

39. Ducarme, C. \& Micha, J-C. (2003). Technique de production intensive du poisson chat africain, Clarias gariepinus. Tropicultura, 21(4), 189198.

40. Effiong, B. N., Sanni, A. \& Fakunle, J. O. (2009). Effect of partial replacement of fishmeal with duckweed (Lemna Pauciscostata) meal on the growth performance of Heterobranchus longifilis fingerlings. Report and Opinion, 1, 76-80.

41. Eglal, A. O., Nour, A. M., Essa, M. A., Zaki, M. A. \& Mabrouk H. A. (2009). Technical and economical evaluation of small scale fish cage culture for youth in the River Nile for Egypt: Effect of stocking density of monosex Nile Tilapia (Oreochromis niloticus) fingerlings. In: Y. Yang, X. Z. Wu, \& Y. Q. Zhou (Eds.), cage aquaculture in Asia: Proceeding of the International symposium on cage aquaculture in Asia, 107- 114. Asian Fisheries Society, Manila, Philippines and Zhejiang University, Hangzhou, China.

42. Ellis, T., North, A. P., Bromage, N. R., Porter, M. \& Gadd, D. (2002). Review paper. The relationship between stocking density and welfare in farmed rainbow trout. Journal of Fish Biology, 61, 493-531.

43. El-Sayed, A. F. M. (1990). Long term evaluation of cotton seed meal as a protein source for Nile Tilapia Oreochromis niloticus. Aquaculture, 84, 315-320.

44. Fagbenro, O. A. \& Sydenham, D. H. J. (1988). Evaluation of Clarias isheriensis Under Semi - intensive Management in Ponds. Aquaculture Nutrition, 5(3), 199- 204.

45. FAO (2004). Situation mondiale des pêches et de l'aquaculture. Rome, 164.

46. Fermon, Y. (2011). La pisciculture de subsistance en étangs en Afrique : manuel technique. Action contre la faim. ACF-International Network, Paris, 276.

47. Finke, M. D. (2002). Complete nutrient composition of commercially raised invertebrates used as food for insectivores. Zoo Biology, 21(3), 269-285. 
48. Froese, R. \& Daniel, P. (2011). "Clarias gariepinus" in Fish Base. December 2011 version.

49. Gilles, S., Dugué, R. \& Slembrouk, J. (2001). Manuel de production du silure africain, Heterobranchus longifilis. Maisonneuve et Larose, Paris, 128.

50. Glencross, B. D., Booth, M. \& Allan, G. L. (2007). A feed is only as good as its ingredients. A review of ingredient evaluation strategies for aquaculture feeds. Aquaculture Nutrition, 13, 17-34.

51. Gorlach-Lira, K., Pacheco, C., Carvalho, L. C. T., Junior, H. N. M. \& Crispim, M. C. (2013). The influence of fish culture in floating net cages on microbial indicators of water quality. Brazilian Journal of Biology, 73(3), 457-463.

52. Griffin, M. E., Wilson, K. A. \& Brown, P. B. (1994). Dietary arginine requirement of juvenile hybrid striped bass. Journal of Nutrition, 124, 888-893.

53. Guillaume, J., Kaushik, S., Bergot, P. \& Metailler, R. (1999). Nutrition et alimentation des poissons et crustacés. Ed. INRA, Paris, 485.

54. Halver, J. E. (1976). Formulating practical diets for fish. Journal of Fisheries Research. Board Can., 33, 1032-1039.

55. Hastings, W. H. (1973). Expériences relatives à la préparation d'aliments des poissons et à leur alimentation. Rapport préparé pour le Projet Régional de Recherche et de Formation Piscicoles, FAO FI: DP/RAF/66/054/1, 24.

56. Hastings, W. H. \& Dickie, L. M. (1972). Feed formulation and evaluation. In J. E. Halver (Eds.), Fish nutrition, 327-374. Academic Press. London.

57. Haylor, G. S. \& Mollah, M. F. A. (1995). Controlled hatchery production of African catfish, Clarias gariepinus: the influence of temperature on early development. Aquatic Living Resources, 8, 431438.

58. Hecht, T. (1996). An alternative life history approach to the nutrition and feeding of Siluroidei larvae and early juveniles. Aquatic Living Resources, 9, 121-133.

59. Hecht, T. (2013). A review of on-farm feed management practices for North African catfish (Clarias gariepinus) in sub-Saharan Africa. In M. R. Hasan \& M. B. New (Eds.), On-farm feeding and feed management in aquaculture, 463-479. FAO Fisheries and Aquaculture Technical Paper No. 583. Rome, FAO.

60. Hecht, T., Oellermann, L. \& Verheust, L. (1996). Perspectives on clariid catfish culture in Africa. Aquatic Living Resources, 9, 197-206. 
61. Hecht, T., Uys, W. \& Britz, P. (1988). The culture of sharptooth catfish (Clarias gariepinus) in southern Africa. South African Natural Science Progress Report No 153, 133.

62. Hêdji, C. C., Kpoguè Gangbazo, D. N. S., Houinato, M. R. \& Fiogbé, E. D. (2014). Valorisation de Azolla spp, Moringa oleifera, son de riz, et de co-produits de volaille et de poisson en alimentation animale: synthèse bibliographique. Journal of Applied Biosciences, 81, 7277 7289.

63. Hengsawat, K., Ward, F. J. \& Jarutjaramorn, P. (1997). The effect of stocking density on yield, growth and mortality of African catfish (Clarias gariepinus Burshell 1822) cultured in cages. Aquaculture, 152, 67-76.

64. Henken, A. M., Machiels, M. A. M., Dekker, W. \& Hogendoorn, H. (1986). The effect of dietary protein and energy content on growth rate and feed utilization of the African catfish Clarias gariepinus (Burchell 1822). Aquaculture, 58, 55-74.

65. Hepher, B. \& Pruginin, Y. (1981). Commercial fish farming. A Wiley Interscience Publication, New York, 261.

66. Hoffman, L. C., Prinsloo, J. F. \& Rukan, G. (1997). Partial replacement of fish meal with either soybean meal, brewer's yeast or tomato meal in the diets of African sharptooth catfish Clarias gariepinus. Water SA, 23, 181-186.

67. Hogendoorn, H. (1979). Controlled propagation of the African catfish, Clarias lazera (C. \& V.): I. Reproductive biology and field experiments. Aquaculture, 17, 323-333.

68. Hogendoorn, H. (1981). Controlled propagation of the African catfish, Clarias lazera (C \& V.): IV. Effect of feeding regime in fingerling culture. Aquaculture, 24 (1-2), 123-131. DOI: 10.1016/00448486(81)90049-1.

69. Hogendoorn, H. (1983). The African catfish (Clarias lazera $C$. et V., 1840). A new species for aquaculture. Doctoral dissertation, Agriculture University, Wageningen, Netherlands, 135.

70. Hogendoorn, H., Jansen, J. A. J., Koops, W. J. \& van Hees, J. P. (1983). Growth and production of the African catfish, Clarias lazera (C. \& V.): II. Effects of body weight, temperature and feeding level in intensive tank culture. Aquaculture, 34 (3-4), 265-285.

71. Holden, M. \& Reed, W. (1978). West African Freshwater Fishes. Nature Handbooks, Longman group Ltd., London, 78.

72. Huisman, E. A. \& Richter, C. J. J. (1987). Reproduction, growth, health control and aquacultural potential of the African catfish, Clarias gariepinus (Burchell 1822). Aquaculture, 63, 1-14. 
73. Idodo-Umeh, G. (2003). Freshwater Fishes of Nigeria (Taxonomy, Ecological Notes, Diets and utilization). Idodo Umeh Publishers Ltd. Benin City, 232.

74. Imorou Toko, I. (2007). Amélioration de la production halieutique des trous traditionnels à poissons (whedos) du delta de l'Ouémé (sud Bénin) par la promotion de l'élevage des poissons-chats Clarias gariepinus et Heterobranchus longifilis. Thèse de doctorat, Facultés universitaires Notre-Dame de la Paix, 127.

75. ISI (1974). Indian standard methods for sampling and test (physical and chemical) for water used in industry. Indian standard Institute, Manak Bhawan, New Delhi, 7.

76. Jackson, A. J., Copper, B. S. \& Matty, A. J. (1982). Evaluation of some plant proteins in complete diets for the Tilapia Sarotherodon mossambicus. Aquaculture, 27, 97 - 109.

77. Jafri, A. K., Jafri, D. K., Khan, M. A., Anwar, M. F., Hassan, A. \& Fanullah, E. R. (1992). On the use of locally available feed stuffs in formulated fish feeds. Proximate composition and gross energy content. In Aquaculture research needs for 2000 A.D., 143-151. Oxford and IBH Publishing Co. Pvt. Ltd., New Delhi.

78. Jamabo, N. A. \& Keremah, R. I. (2009). Effects of stocking density on the growth and survival of the fingerlings of Clarias gariepinus (Burchell, 1822). Journal of Fisheries International, 4 (4), 55-57.

79. Jiwyam, W. (2012). Extensive net cage culture of Nile Tilapia (Oreochromis niloticus) fingerlings in nutrient enriched pond. Our Nature, 10, 61-70.

80. Joseph, K. B., Soderberg, R. W. \& Terlizzi D. E. (1993). An introduction to water chemistry in freshwater aquaculture. NRAC Fact Sheet No: 170.

81. Kanangire, K. (2001). Effets de l'alimentation des poissons avec Azolla sur la production d'un écosystème agro-piscicole en zones marécageuses au Rwanda. Thèse de doctorat, Université Notre-Dame de la Paix, Namur, 220.

82. Kumar, V., Akinleye, A. O., Makkar, H. P. S., Angulo-Escalante, M. A. \& Beker, K. (2010). Growth performance and metabolic efficiency in Nile tilapia (Oreochromis niloticus L.) fed on a diet containing Jatropha platyphylla kernel meal as a protein source. Journal of Animal Physiology and Animal Nutrition, 10. DOI : 10.111/j.14390396.2010.01118.x. 10p.

83. Lacroix, E. (2004). Pisciculture en zone tropicale. MAEP-Direction de la Programmation et de la Prospective (2011). Analyse économique des chaînes de valeurs des filières poisson et crevette. GTZ, GFA Terra Systems, Hamburg, 231. 
84. Lagler, K. F. (1971). Capture, sampling and examination of fishes. In W. E. Ricker (Eds.), Methods for assessment of fish production in freshwaters ( $2^{\text {nd }}$ ed.), 7-44. International Biological Programme, 3. Oxford and Edinbourgh.

85. Laporte, J., Woodgate, S. L., Davis, S. J. \& Gouveia, A. (2009). Combining blood meal with other animal protein sources in compound aquafeed. International Aquafeed. July/August 2008, 12-18. http://www.aquafeed.co.uk.

86. Lazard, J. \& Legendre, M. (1996). La reproduction spontanée du tilapia : une chance ou un handicap pour le développement de l'aquaculture africaine. In R.S.V, Pullin, J. Lazard, M. Legendre, J.B. AmonKothias et D. Pauly (Eds.), Le Troisième Symposium International sur le Tilapia en Aquaculture, 82-98. ICLARM. Conf. Proe.

87. Legendre, M., Teugels, G.G., Cauty, C. \& Jalabert, B. (1992). A comparative study on morphology, growth rate and reproduction of Clarias gariepinus (Burchell 1822), Heterobranchus longifilis valenciennes 1840 and their reciprocal hybrids (pisce:clariidae)", Journal of Fish Biology, 40, 59-79.

88. Legendre, M. \& Lévêque C. (1999). L'aquaculture. In C. Lévêque \& D. Paugy (Eds.), Les poissons des eaux continentales africaines, 425438. IRD, France.

89. Legendre, M., Linhart, O. \& Billard, R. (1996). Spawning and management of gametes, fertilized eggs and embryos in Siluroidei. In M. Legendre \& J-P. Proteau (Eds.), The biology and culture of catfishes, 59-80. Aquatic Living Resources, 9, Paris.

90. Legros, D. (1998). Guide technique pour l'élevage du tilapia. CDI, Bruxelles, 1 ère édition, 45.

91. Lim, C. \& Akinyama, D. (1992). Full fat utilization of soybean meal by fish. Asian Fisheries Science, 5, 181-197.

92. Limbu, S. M. (2015). The effect of floating and sinking diets on growth performance, feed conversion efficiency, yield and cost- effectiveness of African sharptooth catfish, Clarias gariepinus reared in earthen ponds. International Journal of Fisheries and Aquatic Studies, 2(5), 253-259.

93. Machiels, M. A. M. \& Hencken, A. M. (1987). A dynamic simulation model for growth of the African catfish, Clarias garieipnus (Burchell 1822). II: Effect of feed composition on growth and energy metabolism. Aquaculture, 60, 33-63.

94. Mallasen, M., Barros, H. P., Traficante, D. P. \& Camargo A. L. S. (2012). Influence of a net cage tilapia culture on the water quality of 
the Nova Avanhandava reservoir, Sao Paulo state, Brazil. Acta Scientiarum Biological Sciences, 34(3), 289-296.

95. Masser, M. P. \& Wurts, W. A. (1992). Managing recreational fish ponds. World Aquaculture, 23(2), 41-47.

96. Mfwana, I. D., Kasongo, T. G., Ntende, M. B., Katemo, M. B. \& Chocha, M. A. (2016). Comparative study of the performances of growth and rate of survival of the larvae of the two species of the genus Clarias ( $C$. gariepinus and $C$. ngamensis) at the zoological garden of Lubumbashi, DR Congo. International Journal of Innovation and Applied Studies, 17(3), 738-744.

97. Mondal, M. N., Shahim, J., Wahab, M. A., Asaduzzaman, M. \& Yang, Y. (2010). Comparison between cage and pond production of Thai Climbing Perch (Anabas testudineus) and Tilapia (Oreochromis niloticus) under three management systems. Journal of Bangladesh Agricultural University, 8(2), 313-322.

98. Mustapha, M. K., Akinware, B. F., Faseyi, C. A. \& Alade, A. A. (2014). Comparative effect of local and foreign commercial feeds on the growth and survival of Clarias gariepinus juveniles. Journal of Fisheries, 2(2), 106-112. DOI: 10.17017/jfish.v2i2.2014.25

99. Naylor, R. L., Goldburg, R. J., Primavera, J.H., Kautsky, N., Beveridge, M. C. M., Clay, J., Folke, C., Lubchenco, J., Mooney, H. \& Troell, M. (2000). Effect of aquaculture on world fish supplies. Nature, 405, 1017-1024.

100. Ndimele, P. E. \& Owodeinde, F. G. (2012). Comparative Reproductive and Growth Performance of Clarias gariepinus (Burchell, 1822) and Its Hybrid Induced with Synthetic Hormone and Pituitary Gland of Clarias gariepinus. Turkish Journal of Fisheries and Aquatic Sciences, 12, 619-626.

101. Neill, W. H. \& Bryan, J. D. (1991). Responses of fish to temperature and oxygen and response integration through metabolic scope. In D. E. Brune \& J. R. Tomasso (Eds.), Aquaculture and water quality (Advances in World Aquaculture, volume, 3), 30-57. The World Aquaculture Society, Batan Rouge, Louisiana.

102. Ng, W. K., Liew, F. L., Ang, L. P. \& Wong, L. X. (2001). Potential of mealworm (Tenebrio molitor) as an alternative protein source in practical diets for African Catfish, Clarias gariepinus. Agricultural Research, 32(1), 273-280.

103. Ng, W. K. \& Wee, K. L. (1989). The nutritive value of cassava leaf meal in pelleted feed for Nile tilapia. Aquaculture, 83, 45-58.

104. Nguenga, D., Breine, J. J., Teugels, G. G. \& Ollevier, F. (1996). Artificial propagation of the African catfish Heterobranchus longifilis (Siluroidei; Clariidae): Description of a simple technique to avoid 
sacrificing male broodfish for the obtention of milt. Aquaculture, 143, 215-217.

105. Nwadukwe, F. O. (1993). Inducing maturation, ovulation and spawning in the African catfish Heterobranchus longifilis Valenciennes (Pisces; Clariidae), using frog pituitary extract. Aquaculture and Fisheries Management, 24, 625-630.

106. Nwadukwe, F. O., Ayinla, O. A. \& Abby-Kalio, N. J. (1993). Effects of various doses of acetone-dried powdered carp pitutary extract and season on hatchery propagation of Heterobranchus longifilis (Val., 1840) (Pisces; Clariidae). Journal of Aquaculture in the Tropics, 8, 33-40.

107. Nwanna, L. C. (2003). Nutritional value and digestibility of fermented shrimp head waste meal by African catfish Clarias gariepinus. Pakistan Journal of Nutrition, 2, 339-345.

108. Nweke, S. I. \& Ugwumba, A. A. (2005). Effects of replacement of Fishmeal with Duckweed (Lemna paucicostata) meal on the Growth of Clarias gariepinus Burchell, 1822 fingerlings. In Proceedings of the 20 Annual Conference of the Fisheries Society of Nigeria (FISON), 163-167. Port-Harcourt, Nigeria.

109. Nwipie, G. N., Erondu, E. S. \& Zabbey, N. (2015). Influence of Stocking Density on Growth and Survival of Post Fry of the African Mud Catfish, Clarias gariepinus. Fisheries and Aquaculture Journal, 6, 116. doi:10.4172/2150-3508.1000116.

110. Nwokoye C. O., Nwuba L. A. and Eyo J. E. (2007). Induced propagation of African clariid catfish, Heterobranchus bidorsalis (Geoffrey Saint Hillarie, 1809) using synthetic and homoplastic hormones. African Journal of Biotechnology, 6 (23), 2687-2693.

111. Nyanti, L., Hii, K. M., Sow, A., Norhadi, I. \& Ling, T. Y. (2012). Impacts of Aquaculture at different Depths and Distances from cage culture sited in Batang $\mathrm{Ai}$ Hydroelectric Dam Reservoir Sarawak, Malaysia. World Applied Sciences Journal, 19(4), 451-456.

112. Ochang, S. N., Fagbenro, O. A. \& Adebayo, O. T. (2007). Growth Performance, Body Composition, Haematology and Product Quality of the African Catfish (Clarias gariepinus) Fed Diets with Palm Oil. Pakistan Journal of Nutrition, 6(5), 452-459.

113. Ogunji, J. O. \& Wirth, M. (2001). Alternative protein sources as substitutes for fish meal in the diet of young Tilapia Oreochromis niloticus. Israeli Journal of Aquaculture - Bamidgeh, (53), 34-43.

114. Okore, O. O., Ekedo, C. M., Ubiaru, P. C. \& Uzodinma, K. (2016). Growth and Haematological Studies of African Catfish (Clarias gariepinus) Juveniles Fed with Housefly Larva (Musca 
dometica) as Feed Supplement. International Journal of Agriculture and Earth Science, 2 (3), 21-30. www.iiardpub.org.

115. Olukunle, O. A. \& Falaye, A. E. (1998). Use of sesame seed cake as replacement for fish meal in diets for catfish, Clarias gariepinus (Burchell, 1822). Applied Tropical Agriculture, 3(2), 8691.

116. Oluwashina, M. M. \& Solomon, R. J. (2012). Comparative study of feed utilization and growth rate in Heteroclarias. Researcher, 4(9), 45-54. http://www.sciencepub.net/researcher.

117. Orire, A. M., Omotoyinbo, S. O. \& Sadiku, S. O. E. (2013). The Growth and Body Composition of Clarias gariepinus Fingerlings Fed Combined Different Sources of Lipid. Journal of Aquaculture Research and Development, 4(4), 1-5.

http://doi:10.4172/2155-9546.1000182.

118. Otémé, Z. J., Hem, S. \& Legendre, M. (1996). New species of catfish for the development of African fish farming. In M. Legendre \& J. P. Proteau (Eds.), The Biology and Culture of Catfishes, 207-217. Aquatic Living Resources, 9.

119. Otubusin, S. O. (1997). Cage culturability of some commercially important fish species in Lake Kainji, Nigeria. Tropical freshwater Biology, 6, 41-47.

120. Otubusin, S. O., Ogunleye, F. O. \& Agbebi, O. T. (2009). Feeding trials using local protein sources to replace fishmeal in pelleted feeds in catfish (Clarias gariepinus, Burchell 1822) culture. European Journal of Scientific Research, 31, 142-147.

121. Otubusin, S. O. \& Olaitan, O. O. (2001). The production of cat fish (Clarias gariepinus in floating bamboo net-cage system in Nigeria. ASSET, 1(1), 77-82.

122. Otubusin, S. O., Olaofe, O. O. \& Agbebi, O. T. (2004). High yields and growth catfish (Clarias gariepinus) in floating bamboo net cage system in Nigeria. Nigeria Journal of Science. Sci. Ass. of Nig., 12 .

123. Paugy, D., Lévêque, C. \& Teugels, G. G. (2004). Faune des poissons d'eaux douces et Saumâtres de l'Afrique de l'Ouest. Faune Tropicale. Edit. IRD. Paris. 815.

124. Pham, A. (1975). Données sur la production en masse d'alevins de Clarias lazera Val. à la station de Bouaké (Côte d'Ivoire). In Notes Doc. Pêche Piscic. nouvelle série $n^{\circ} 10,49-57$. CTFT, Nogent-surMarne, France.

125. Pillay, T. V. R. (1990). Aquaculture: principles and practices. Fishing New Books: Oxford, 575. 
126. Pruszyński, T. (2003). Effects of feeding on ammonium excretion and growth of the African catfish (Clarias gariepinus) fry. Czech Journal of Animal Science, 48(3), 106-112.

127. Richir, J. (2004). Valorisation des produits agro-industriels dans l'alimentation du poisson-chat africain, Clarias gariepinus (Burchell, 1822), au Rwanda. Mémoire présenté pour l'obtention du grade de licencié en Sciences biologiques. Facultés Universitaires Notre-Dame de la Paix, Namur, 87.

128. Richter, C. J. J. (1976). African catfish, Clarias lazera C. et V., a new possibility for fish culture in tropical regions? Misc. Pap. Landbouwhogesh, Wageningen, 13, 51-71.

129. Richter, C. J. J., Viveen, W. J. A. R., Eding, E. H., Sukkel, M., Rothuis, A. J., Van Hoof, M. F. P. M., Van Den Berg, F. G. J. \& Oordt P. G. W. J. (1987). The significance of photoperiodicity, water temperature and an inherent endogenus rhythm for the production of viable eggs by the African catfish, Clarias gariepinus, kept in subtropical ponds in Israel and under Israeli and Dutch hatchery conditions. Aquaculture, 63, 169-185.

130. Rukera Tabaro, S., Micha, J.-C. \& Ducarme, C. (2005). Essais d'adaptation de production massive de juvéniles de Clarias gariepinus en conditions rurales. Tropicultura, 23(4), 231-244.

131. Sadiku, J. K. (1995). Digestibility, apparent amino acid available and waste generation potential of soybean flour - poultry meat blend based diets for tilapia fingerlings. Survey NIFFR, New Bussa, Nigeria Techniques on the Anti-nutrient Contents of Baobab Seeds (adansonia digitata). Aquaculture Research, 26, 651-657.

132. Salami, A. A., Fagbenro, O. A. \& Sydenham, D. H. J. (1993). The production growth of clarid catfish hybrids in concrete tanks. The Isreal journal Aquaculture Bamidgeh, 45(1), 18-25.

133. Shiau, S. Y., Chuang, J. L. \& Sun, C. L., 1987. Inclusion of soybean meal in Tilapia (Oreochromis niloticus X O. aureus) diets at two protein levels. Aquaculture, 65, 251-261.

134. Siddhuraju, P. \& Becker, K. (2001). Preliminary nutritional evaluation of mucuna seed meal (Mucuna pruriens var. utilis) in common carp (Cyprinus carpio L.): An assessment by growth performance and feed utilization. Aquaculture, 196, 105-123.

135. Siti-zahrah, A., Padilah, B., Azila, R., Rimatulhana, R. \& Shahidan, H. (2008). Multiple streptococcal species infection in cagecultured Red Tilapia But showing similar clinical signs. In M. G. Bonded-Reantaso, C. V. Mohan, M. Crumlish, \& R. P. Subasinghe (Eds.), Disease in Asian Aquaculture VI, 313-320. Fish Health Section, Asian Fisheries Society, Manila, Philippines. 505. 
136. Sogbesan, A. O., NAjuonu, N., Musa, B. O. \& Adewole A. M. (2006). Harvesting techniques and evaluation of maggot meal as animal dietary protein source for "Heteroclarias" in outdoor concrete tanks. World Journal of Agricultural Sciences, 2(4), 394-402.

137. Sotolu, A. O. (2010). Growth performance of Clarias gariepinus (Burchell, 1822) fed varying inclusions of Leucaena leucocephala seed meal. Tropicultura, 28(3), 168-172.

138. Tacon A. G. J. (1990). Standard methods for the nutrition and feeding of farmed fish and shrimp. Argent Laboratories Press, Redmond, Washington, USA, 454.

139. Tacon, A. G. J. (1993). Feed formulation and on-farm feed management. In M. B. New, A. G. J. Tacon, \& I. Csavas (Eds.), Farmmade aquafeeds, 64-74. Proceedings of the FAO/AADCP Regional Expert Consultation on farm-made Aquafeeds. Bangkok, FAORAPA/AADCP.

140. Tacon, A. G. J. (1996). Feeding tommorow's fish. World aquaculture, 27(3), 20-32.

141. Tacon, A. G. J., Hasan, M. R. \& Subasinghe, R. P. (2006). Use of fishery resources as feed inputs for aquaculture development: trends and policy implications. Rome, Italy: FAO. FAO Fisheries Circular No.1018, 99.

142. Teugels, G. G. (1986). A systematic revision of the African species of the genus Clarias (Pisces: Clariidae). Annales Musee Royal de L'Afrique Centrale. Science Zoolgiques, 247, 1-199.

143. Uys, W. (1989). Aspects of the nutritional physiology and dietary requirements of juvenile and adult sharptooth catfish, Clarias gariepinus (Pisces; Clariidae). Ph.D. Thesis, Rhodes University, Grahamstown, 190.

144. Uys, W. \& Hecht, T. (1985). Evaluation and preparation of an optimal dry feed for the primary nursing of Clarias gariepinus larvae (pisces: Clariidae). Aquaculture, 47, 173-183.

145. Vandewalle, P. (2002). Systématique des poissons, mollusques et crustacés. Notes de cours de DES Aquaculture. ULg/FUNDP, 197.

146. Van Weerd, J. H. (1995). Nutrition and growth in Clarias species - a review. Aquatic Living Resources, 8, 395-401.

147. Viveen, W. J. A. R., Richter, C. J. J., Oordt, P. G. W. J. v., Janssen, J. A. L. \& Huisman, E. A. (1985). Manuel pratique de pisciculture du poisson-chat africain (Clarias gariepinus). Départment de Pisciculture et de Pêche de l'Université Agronomique de Wageningen (Pays-Bas), 92.

148. Wedekind, H. (1991). Investigations on the product quality of African catfish (Clarias gariepinus) in Dependence on genetic origin, 
feeding, sex and slaughter age. Dissertation, University Gottingen, Gottingen, Germany.

149. Więcaszek, B., Krzykawski, S., Antoszek, A., Kosik, J. \& Serwotka, P. (2010). Morphometric characteristics of the juvenile North African catfish Clarias gariepinus (Burchell, 1822) from the heated water aquaculture. Electronic Journal of Polish Agricultural Universities (EJPAU), 13, (2).

150. Wood, J. (1993). Selecting equipment for producing farm made aquafeeds. In M. B. New, A. J. G. Tacon \& I. Csavas I. (Eds), Farm Made Aquafeeds, 135-147. Proceedings of the FAO/AADCP Regional Expert Consultation on Farm-Made Aquafeeds, Bangkok, Thailand.

151. Yaqoob, M., Ali, M. R. \& Mehmood, S. (2010). Comparison of growth performance of major and Chinese carps fed on floating and sinking pelleted supplementary feeds in ponds. Pakistan Journal of Zoology, 42(6), 765-769.

152. Yashouv, A. \& Chervinski, J. (1971). Preliminary experiments on the growth of Tilapia aurea in seawater ponds. Bamidgeh, 23, 125129.

153. Zamal, H., Barua, P., Uddin, B. \& Islam, K. S. (2008). Application of ipil-ipil leaf meal as feed Ingredient for monosex tilapia fry (Oreochromis niloticus) in terms of growth and economics. Aquaculture Asia magazine, April-June, 31-33.

154. Zanatta, A. S., Perbiche-Neves, G., Ventura, R., Ramos, I. P. \& Carvalho E. D. (2010). Effects of a small fish cage farm on zooplankton assemblages (Cladocera and Copepoda: Crustacea) in a sub-tropical reservoir (SE Brazil). Pan American Journal of Aquatic Sciences, 5(4), 530-539.

155. Zeinhom, M. M., Ebrahim, M.S. \& Ebrahim, E. M. (2010). Effect of feeding rates and frequencies on growth performance, feed efficiency and body composition of African catfish, Clarias gariepinus Burchell, 1822. Journal of Arabian Aquaculture Society, 5(2), 207220. 